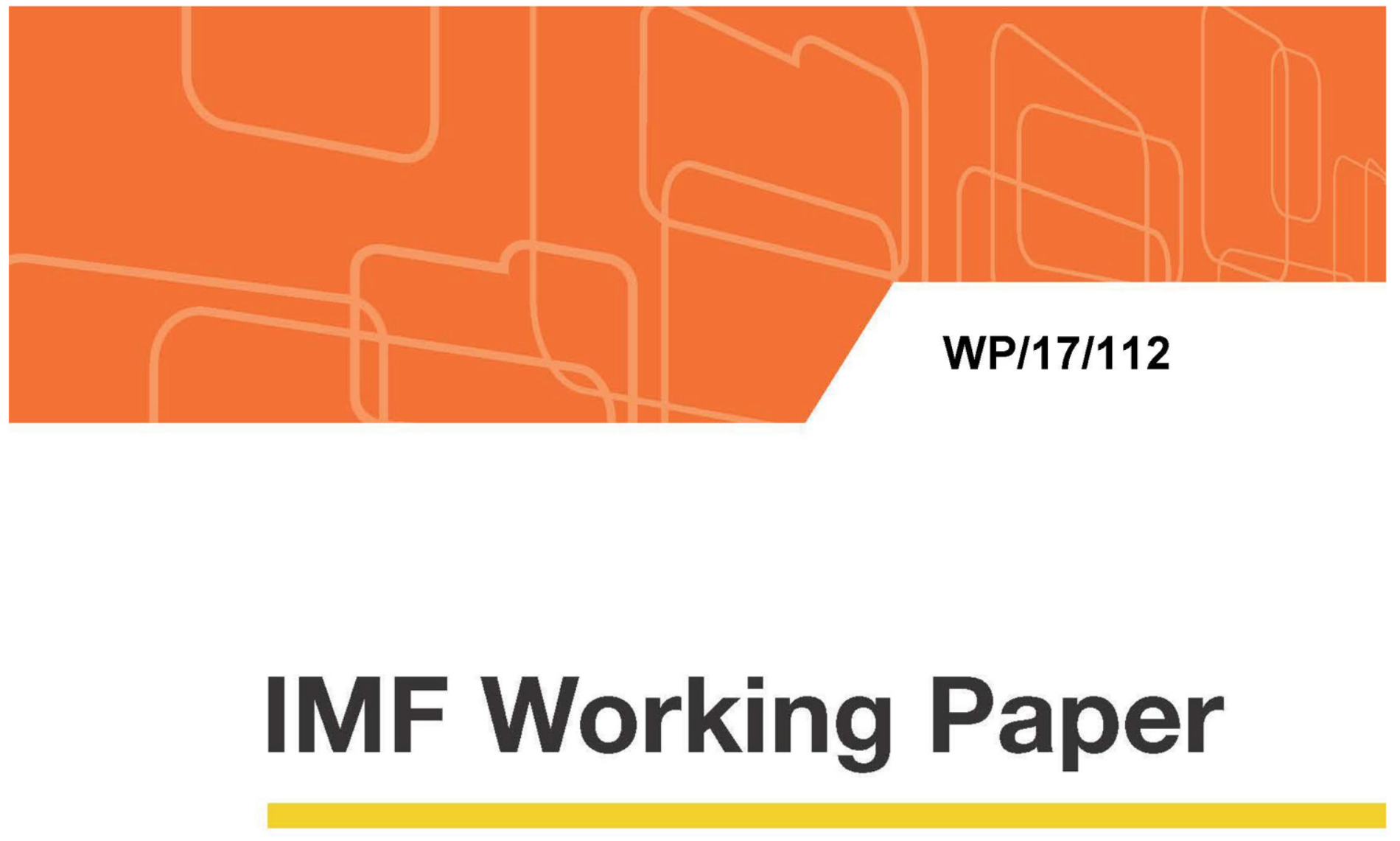

\title{
Farms, Fertiliser, and Financial Frictions: Yields from a DSGE Model
}

by Sébastien E. J. Walker

IMF Working Papers describe research in progress by the author(s) and are published to elicit comments and to encourage debate. The views expressed in IMF Working Papers are those of the author(s) and do not necessarily represent the views of the IMF, its Executive Board, or IMF management.

$$
\text { I N T E R N A T I O N A L M O N E T A R Y F U N D }
$$




\title{
WP/17/112
}

\section{IMF Working Paper}

\author{
Farms, Fertiliser, and Financial \\ Frictions: Yields from a DSGE Model
}

by Sébastien E. J. Walker

IMF Working Papers describe research in progress by the author(s) and are published to elicit comments and to encourage debate. The views expressed in IMF Working Papers are those of the author(s) and do not necessarily represent the views of the IMF, its Executive Board, or IMF management.
I $\mathrm{N}$
N T E R N A T I O N A L
$M O N E T A R Y$
$F \cup N D$ 


\title{
IMF Working Paper
}

\author{
African Department
}

\author{
Farms, Fertiliser, and Financial Frictions: Yields from a DSGE Model $^{1}$ \\ Prepared by Sébastien E. J. Walker
}

Authorized for distribution by Dhaneshwar Ghura

April 2017

\begin{abstract}
IMF Working Papers describe research in progress by the author(s) and are published to elicit comments and to encourage debate. The views expressed in IMF Working Papers are those of the author(s) and do not necessarily represent the views of the IMF, its Executive Board, or IMF management.
\end{abstract}

\begin{abstract}
This paper develops a Dynamic Stochastic General Equilibrium (DSGE) model with a financial accelerator which captures key features of low-income countries (LICs). The predominance of supply shocks in LICs poses distinct challenges for policymakers, given the negative correlation between inflation and the output gap in the case of supply shocks. Our results suggest that: (1) in the face of a supply-side shock, the most desirable interest rate rule involves simply targeting current inflation and smoothing the policy interest rate; and (2) ignoring financial frictions when evaluating policy rules can be particularly problematic in LICs, where financial frictions loom especially large.

JEL Classification Numbers: E52, F41, O23

Keywords: Monetary policy, Africa, financial frictions, foreign capital flows, DSGE models, supply shocks.

Author’s E-Mail Address: swalker@imf.org
\end{abstract}

\footnotetext{
${ }^{1}$ This paper is part of a research project on macroeconomic policy in low-income countries supported by the UK Department for International Development (DFID). This was my job market paper written under the supervision of Christopher Adam, whom I thank for his invaluable help. Thanks are due to Christopher Bowdler, Giovanni Melina, Xican Xi, and to conference and seminar participants at the 2013 Royal Economic Society Easter Training School, the 2013 CSAE Conference, the University of Oxford, and the IMF for helpful comments. Any mistakes are my own.
} 


\section{Contents}

1 Introduction $\underline{4}$

2 Background $\underline{\mathbf{5}}$

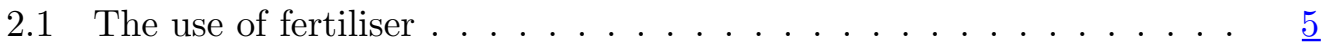

2.2 Existing literature . . . . . . . . . . . . . $\underline{6}$

3 The model $\quad \underline{\mathbf{7}}$

3.1 Households ...................... $\underline{8}$

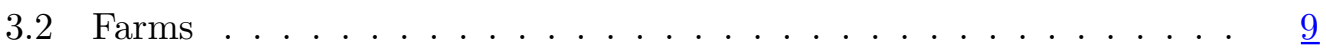

3.2.1 Agricultural production . . . . . . . . . . . . $\underline{9}$

3.2 .2 Working capital . . . . . . . . . . . . . . 11

3.2 .3 Financial frictions . . . . . . . . . . . . . . 12

3.2.4 Net worth and demand for fertiliser . . . . . . . . . 14

3.3 Wholesale prices . . . . . . . . . . . . . . 17

3.4 Retailers, price setting, and inflation . . . . . . . . . . $\underline{18}$

3.5 Real exchange rate and cost of fertiliser . . . . . . . . . . $\underline{20}$

3.6 Government budget constraint . . . . . . . . . . . $\underline{20}$

3.7 Resource constraint . . . . . . . . . . . . . . 20

3.8 Balance of payments . . . . . . . . . . . . . . $\underline{21}$

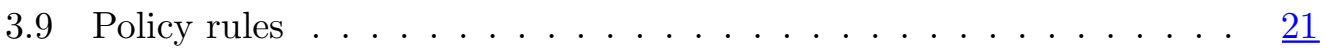

4 Baseline parameterisation $\underline{22}$

5 Results and policy analysis $\underline{\mathbf{2 4}}$

5.1 Baseline results . . . . . . . . . . . . . . . 24

5.2 Alternative policy rules . . . . . . . . . . . . $\underline{30}$

5.3 Endogenous fertiliser subsidy ............. $\underline{40}$

6 Conclusions $\quad \underline{43}$

Appendix 1 Derivation of the financial accelerator equations $\quad \underline{44}$

Appendix 2 Model equations $\quad \underline{46}$

Appendix 3 List of variables and parameters $\quad \underline{49}$

References $\quad \underline{51}$ 


\section{Introduction}

"The frequency of agricultural shocks caused by extreme weather events has risen sharply over the past decade, and the resulting surge in food commodity prices has hit not only consumers, but everybody in the food supply chain, including farmers, agricultural traders and food manufacturers." (Financial Times, April 11th 2014.)

This paper develops a model which yields (1) an improved understanding of agricultural supply shocks and their amplification by financial frictions in the context of low-income countries (LICs); and (2) monetary policy rules useful for managing such shocks. Our Dynamic Stochastic General Equilibrium (DSGE) model builds upon the 'financial accelerator' model elaborated in Bernanke et al. (1999) [BGG] and Gertler et al. (2007) [GGN] while borrowing from the framework for "managing aid surges in Africa" developed in Adam et al. (2008, 2009). This paper's contribution to its field of research is to adapt the mechanism of the financial accelerator to agricultural production as well as to take into account the specific constraints faced by macroeconomic-policy makers in LICs.

A critical feature of many LICs is that agriculture accounts for a relatively large proportion of GDP, and an even larger proportion of employment and therefore livelihoods; in 2008 in Kenya, agricultural value added represented $23 \%$ of GDP, while $79 \%$ of the population was rural (Karugia et al., 2010). As a result, volatile weather conditions can be a source of substantial shocks to the economies of LICs and to the living conditions of their populations. Additional shocks that can affect agricultural production, as well as the economy more generally, notably come from the volatile cost of imported inputs, such as fertiliser and oil (the cost of the two being closely linked in practice); this volatility arises from fluctuations of the exchange rate as well as of the world cost of inputs.

These stylised facts help to explain the predominance of supply-side shocks over demand-side shocks notable of LICs (Adam et al., 2010), which presents challenges for monetary policy. Indeed, supply shocks lead to negatively correlated changes in the output gap and in inflation, which means that inflation-targeting frameworks attractive to advanced economies can exacerbate output volatility. For example, Portillo et al. (2015) find that the correlation between headline inflation and output increases with income per capita at business-cycle frequency, starting from negative values for most LICs. Hence the need for a model which captures the details of the supply side of LICs to generate useful policy response functions.

The central premise upon which our model is built is that farmers must borrow to purchase fertiliser in advance of receiving revenue from selling their production, and therefore face a 'cash-in-advance' constraint. This borrowing is subject to an external finance premium (EFP), i.e., a premium over the opportunity cost of funds raised internally (such as retained earnings) when borrowing from an external source. The financial frictions caused by the EFP are amplified by shocks to agricultural production from volatile weather conditions and imported fertiliser costs, which in turn further constrain production - this is the financial accelerator expounded below.

On the one hand, the fact that the supply shocks discussed above are exacerbated by the financial accelerator could worsen the trade-off between moderating inflation and stabilising output. On the other hand, there is a potential for monetary policy to ease borrowing costs for farmers, through a reduction in the 'risk-free interest 
rate' to compensate for a higher EFP, allowing them to expand production and lower prices; this suggests a less-unfavourable trade-off than might otherwise be the case. Given the importance of imported fertiliser in our model, one might expect that a degree of exchange rate management would help to stabilise the economy. We use the model developed below to weigh up these considerations.

Our baseline analysis, in which the monetary authority follows a Taylor-type interest rate rule, replicates the stylised fact that adverse supply shocks lead to a rise in inflation and a fall in output. We find that the financial accelerator materially amplifies the effects of both types of shock considered. We examine the properties of a range of alternative interest rate rules, in the face of supply shocks, and find the most desirable one (in a sense explained later) to involve simply targeting current inflation and smoothing the policy interest rate. Under this rule, we find that in the case of the weather shock alone, output falls by noticeably less when the financial accelerator operates than when it does not (while inflation is somewhat more volatile). This points to possible dangers in abstracting from financial frictions when assessing the merits of different policy rules, and particularly so in an LIC such as Kenya where financial frictions loom especially large. Finally, our simulations indicate that a countercyclical fertiliser subsidy helps to stabilise the economy under the restrictive assumption that government expenditure is funded exclusively by aid and (in effect) lump-sum taxes.

\section{Background}

This section explains the role given to fertiliser in our analysis, then provides a brief overview of relevant literature on the topic.

\subsection{The use of fertiliser}

We will model the Kenyan economy by assuming that GDP consists entirely of agricultural output, and that this output is produced using exclusively labour and fertiliser, as explained later. While this is clearly unrealistic at the microeconomic level, we believe that this is a useful and not unduly restrictive simplification at the macroeconomic level. We parameterise the model in such a way as to exaggerate the amount of fertiliser used in aggregate, to compensate for the fact that we assume away other imported goods and production inputs (e.g., oil) which are a source of supply-side shocks. This section provides background information on the use of fertiliser in Kenya to motivate the choice of this production input as an example to frame the discussion of our model.

Our analysis will focus on the use of inorganic ('chemical') fertiliser, as opposed to organic fertiliser such as manure or compost. While farmers often use fertiliser of the organic sort, this type has two disadvantages: the rate at which organic material decomposes releasing nutrients cannot be controlled, so that plants may not receive the nutrients when they need them; and the nutrient content of organic material is low, if such material is available at all. Therefore, it is generally not possible to meet crop nutrient demands through organic fertiliser alone (Morris et al., 2007).

Kenya has one of the highest rates of fertiliser use per hectare cultivated in subSaharan Africa (Ariga et al., 2006). When expenditure on inorganic fertiliser (before transport and other additional costs) peaked in 2008 it equalled approximately half- 
a-percent of GDP. ${ }^{1}$ However, once transport costs, port charges, firm markups, etc., are included, the farm-gate price can be double the initial price (Ariga et al., 2006), suggesting that farmers' expenditure on fertiliser reached about 1\% of GDP. Kenya does not currently have facilities to produce fertiliser, so it must all be imported. A large proportion of these imports are from Romania, Ukraine, the USA, Europe, the Middle East, and South Africa (Ariga et al., 2006). International prices for fertiliser are normally quoted in US Dollars, and importing fertiliser requires shortterm financing in large amounts (Morris et al., 2007). This provides two sources of shocks for the local-currency price of fertiliser, since a currency depreciation can exacerbate the effect of an increase in the world fertiliser price, as in 2011 when the price of fertiliser in Kenyan Shillings rose by $32 \% .^{2}$

Use of fertiliser is not limited to large farms or wealthy farmers: in their nationwide survey Ariga et al. (2006) find that its use intensity is roughly equal across small and large farms and across wealth groups in Kenya. However, the authors find that higher-income farmers use fertiliser more consistently across the different survey periods than lower-income farmers; and while the proportion of households using fertiliser credit (whether formal or informal) in the survey's different wealth groups is of a similar order of magnitude, richer farmers are more likely to buy fertiliser with credit than poorer farmers, suggesting that access to credit is a constraint on fertiliser use. These observations support the inclusion of financial frictions which are binding on fertiliser purchases in our model.

Duflo et al.'s (2011) randomised trial found that offering small and time-limited discounts on fertiliser to farmers in Western Kenya increased their use of fertiliser and crop yields, by overcoming present-bias which leads farmers not to invest in fertiliser; they found that this yields higher welfare gains than either no subsidies or heavy subsidies. In 2013, the Kenyan government introduced subsidies on fertiliser worth roughly $30 \%$ of its market price. These subsidies are targeted at small farmers and there were reports of supply delays and shortages; therefore, we will treat this figure as an upper bound on the subsidy rate assumed in our analysis.

\section{$2.2 \quad$ Existing literature}

Laxton and Pesenti (2003) develop a variant of the IMF's Global Economy Model to compare the performance of different monetary policy rules in small open emerging economies. They seek to capture features of such economies with, notably, a reliance on trade that makes them more exposed to external fluctuations than advanced economies, and a higher vulnerability to both demand- and supply-side shocks compared to their higher-income counterparts. They find that Taylor (1993)type rules (where interest rates react to contemporaneous values of inflation and the output gap) and Levin et al. (2003)-type rules (where interest rates are set based on their lag, forecast inflation, and the contemporaneous output gap) perform well in their simulation of a relatively closed economy, but that such rules may be inefficient when applied to small open economies, since they respond too weakly to forecast inflation and too strongly to output gap movements. However, the authors find

\footnotetext{
${ }^{1}$ Our calculations, based on World Bank data using total fertiliser consumption and the free-on-board bulk price of diammonium phosphate (DAP). DAP is the main sort of fertiliser used in Kenya and its price tends to be similar to that of the other main kinds of fertiliser used, namely calcium ammonium nitrate (CAN) and nitrogen phosphorous potassium (NPK) (Ariga et al., 2006, 2008).

${ }^{2}$ Business Daily Africa, October 14th 2012.
} 
that a simple modified Levin et al. (2003)-type rule that responds more strongly to forecast inflation may produce better macroeconomic performance in the economies under consideration.

Aguiar and Gopinath (2007) study business cycles in emerging markets (EMs) by estimating a standard real business cycle (RBC) model with data from Mexico and Canada to represent emerging and developed markets respectively. They find that in EMs shocks to trend growth (as opposed to transitory fluctuations around a stable trend) are the primary source of fluctuations, and therefore argue that in EMs 'the cycle is the trend'. However, García-Cicco et al. (2010) come to starkly different conclusions estimating an augmented RBC model using Argentinian and Mexican data for a longer period. Their augmented model incorporates preference shocks, country-premium shocks, and a "realistic" debt elasticity of the country premium. In contrast to Aguiar and Gopinath (2007), they find that permanent productivity shocks play a negligible role in explaining fluctuations, while the stationary component of total factor productivity explains most of the predicted movements in output growth and half of the growth in private consumption. This supports our strategy of using shocks to (stationary) agricultural productivity as one main source of supply-side shocks in the case of Kenya. Moreover, García-Cicco et al. (2010) interpret their results as suggesting that a promising area for future research is the analysis of dynamic stochastic models of the emerging economy with micro-founded financial imperfections.

EMs are attracting much attention from macroeconomists. For example, Ozcan and Unsal (2010) develop a GGN-style model for Turkey to study the effects of sudden stops in capital flows arising from an international financial crisis. The same cannot be said of LICs in general, and, in particular, we are not aware of any previous attempts to adapt the financial accelerator mechanism to an LIC. Our paper addresses this gap in the literature.

\section{The model}

Our model starts from that of GGN, which is a relatively standard New Keynesian small open economy model to which the financial accelerator mechanism of BGG is incorporated. In the GGN model, perfectly competitive entrepreneurs produce a single type of wholesale good of which a portion is exported and the remainder is sold to domestic retailers; the retailers differentiate the goods and set prices in Calvo (1983) fashion, which is the source of nominal price rigidity. The entrepreneurs need external finance to buy capital goods from domestic capital producers, so they borrow from households via financial intermediaries; the financial frictions in the model give rise to a countercyclical EFP which is the source of the financial accelerator mechanism.

We adapt the GGN model to an LIC context by replacing the entrepreneurs with farmers who use wholly imported fertiliser (which 'depreciates' at a rate of 100\%) and domestic labour to produce their wholesale output. We also replace the CobbDouglas production function typical of this literature with a more general constant elasticity of substitution (CES) production function. The wholesale goods are sold to the rest of the world, to the government, and to retailers; the latter differentiate the goods before selling them on to households. Households also consume imported retail goods. The fertiliser is subsidised by the government, whose expenditure is entirely funded by budgetary aid from overseas and taxes. Figure 1 provides an 
overview of the model. Appendix 2 lists the final set of equations use to simulate the model, and Appendix 3 lists and defines all of the variables and parameters of the model alphabetically.

\section{Figure 1. Model overview}

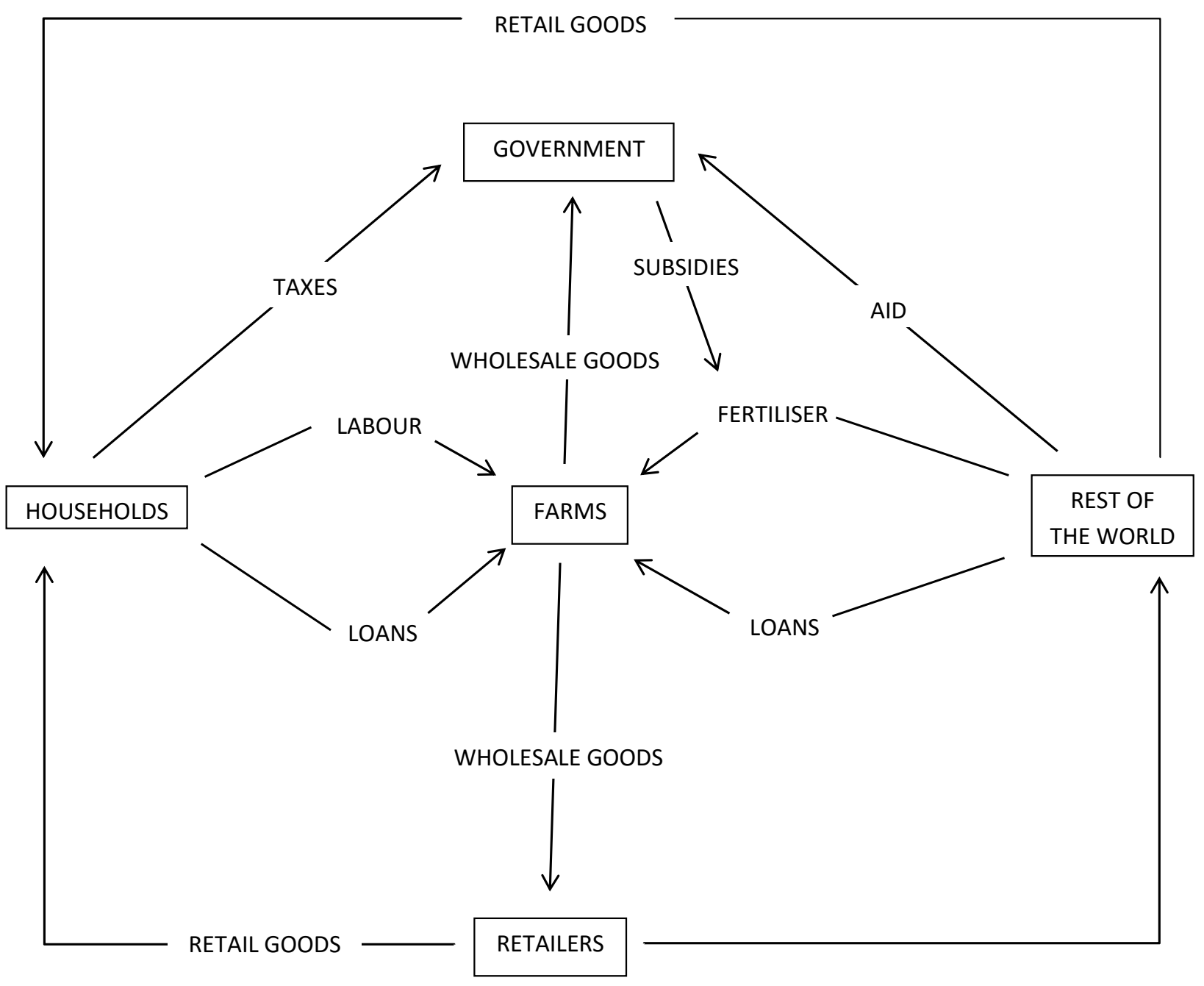

\subsection{Households}

Let $C_{t}$ be a composite of home and imported retail goods, $C_{t}^{H}$ and $C_{t}^{M}$, respectively. The following CES index then defines household preferences over consumption:

$$
C_{t}=\left[(\gamma)^{1 / \rho}\left(C_{t}^{H}\right)^{(\rho-1) / \rho}+(1-\gamma)^{1 / \rho}\left(C_{t}^{M}\right)^{(\rho-1) / \rho}\right]^{\rho /(\rho-1)},
$$

with $\gamma \in(0,1)$ a parameter reflecting the relative share of home and imported goods in domestic consumption. The corresponding consumer price index $(\mathrm{CPI}), P_{t}$ is

$$
P_{t}=\left[(\gamma)\left(P_{R, t}^{H}\right)^{1-\rho}+(1-\gamma)\left(P_{R, t}^{M}\right)^{1-\rho}\right]^{1 /(1-\rho)},
$$


where $P_{R, t}^{H}$ and $P_{R, t}^{M}$ are the (domestic-currency) prices of the home and imported retail goods, respectively. Household intertemporal utility is given by

$$
U_{0}=\mathbb{E}_{0} \sum_{t=0}^{\infty} \beta^{t} \frac{\left[\left(C_{t}\right)^{1-\varsigma}\left(1-L_{t}\right)^{\varsigma}\right]^{1-\nu}}{1-\nu},
$$

with $L_{t}$ the quantity of household labour supplied, $\beta \in(0,1)$ the quarterly discount factor, $\nu \geq 0$ the inverse of the intertemporal elasticity of substitution, and $\varsigma \in(0,1)$ a parameter reflecting households' preference for leisure relative to consumption.

Denote $W_{t}$ the nominal wage; $\Pi_{t}$ real dividends (paid to domestic households by domestic retail firms); $B_{t}^{H}$ nominal household holdings of debt emitted by domestic farms; and $i_{t}$ the domestic nominal interest rate. The household budget constraint is then

$$
C_{t}=\frac{W_{t}}{P_{t}} L_{t}+\Pi_{t}-\frac{B_{t+1}^{H}-\left(1+i_{t-1}\right) B_{t}^{H}}{P_{t}} .
$$

The (first-order) optimal consumption allocation condition, which is obtained by maximising $C_{t}$ subject to $P_{R, t}^{H} C_{t}^{H}+P_{R, t}^{M} C_{t}^{M}$ being equal to a given constant, is

$$
\frac{C_{t}^{H}}{C_{t}^{M}}=\frac{\gamma}{1-\gamma}\left(\frac{P_{R, t}^{H}}{P_{R, t}^{M}}\right)^{-\rho}
$$

Substituting the expression for $C_{t}$ into the instantaneous utility function, and maximising with respect to $L_{t}$, yields the following (first-order) optimality condition for labour supply:

$$
(1-\varsigma) \frac{1}{C_{t}} \frac{W_{t}}{P_{t}}=\varsigma \frac{1}{1-L_{t}} .
$$

Finally, maximising the household's intertemporal utility, subject to the summation over $t$ of the household's budget constraints, and with respect to $C_{t}$ and $B_{t+1}$, yields the following (first-order) optimality condition for consumption and saving:

$$
\lambda_{t}=\beta \mathbb{E}_{t}\left[\lambda_{t+1}\left(1+i_{t}\right) \frac{P_{t}}{P_{t+1}}\right],
$$

where $\lambda_{t}$, the Lagrangian multiplier on the budget constraint at time $t$, which is also the marginal utility of the consumption index at $t$, is given by

$$
\lambda_{t}=(1-\varsigma)\left(C_{t}\right)^{(\nu-1)(\varsigma-1)-1}\left(1-L_{t}\right)^{\varsigma(1-\nu)} .
$$

\subsection{Farms}

\subsubsection{Agricultural production}

There is a continuum of farms ${ }^{3}$ over $[0,1]$, each of which produces homogeneous wholesale goods with a CES production function $Y_{t}$, given by

$$
Y_{t}=\omega_{t} A_{t}\left[\alpha_{M} M_{t}^{\delta}+\alpha_{L} L_{t}^{\delta}\right]^{1 / \delta}
$$

\footnotetext{
${ }^{3}$ We will use the terms 'farm' and 'farmer' interchangeably.
} 
where $\omega_{t}$ is a firm-specific productivity shock; $A_{t}$ is a common productivity factor; $M_{t}$ is an imported intermediate good (e.g., fertiliser); $L_{t}$ is the labour input; $\alpha_{L}$ and $\alpha_{M}$ are respectively labour and fertiliser distribution parameters (in a sense explained below); and $\delta \in(-\infty, 0)$ is a parameter related to the elasticity of substitution between fertiliser and labour, $\Sigma$, by $\delta=(\Sigma-1) / \Sigma \Longleftrightarrow \Sigma=1 /(1-\delta)$. As $\delta \rightarrow-\infty$ we have $\Sigma \rightarrow 0$, so the production function becomes Leontief (fixed proportions); while as $\delta \rightarrow 0$ we have $\Sigma \rightarrow 1$, so the production function becomes Cobb-Douglas if (and only if) $\alpha_{L}+\alpha_{M}=1$. The BGG model and, as far as we are aware, all of the literature which stemmed from it, use the Cobb-Douglas production function. In contrast, we will use the more general CES production function, which allows us to impose a relatively low degree of substitutability between labour and fertiliser (while stopping short of the zero-substitutability Leontief function). Setting $\Sigma$ strictly below 1 implies that labour and fertiliser are complements in production, which is a widely held view according to Lamb (2003); this is consistent with the notion that higher fertiliser use requires additional labour for applying the fertiliser, and for harvesting and transporting the additional produce that results.

Our approach is supported by recent empirical evidence which favours CES production functions at business cycle frequencies with an elasticity of substitution parameter well below unity (Cantore and Levine, 2012). While the distribution parameters in a Cobb-Douglas production function represent shares of income, this is not the case with the more general CES production function, since they have dimensions which depend on the measurement units of the factors of production (ibid.). We therefore follow Cantore and Levine's (2012) "re-parameterization" approach, expressing the distribution parameters in terms of the factor income shares and of the model's endogenous variables. ${ }^{4}$ Thus, we have

$$
\alpha_{M}=S_{M}\left(\frac{\widehat{Y}}{\widehat{M}}\right)^{\delta}
$$

and

$$
\alpha_{L}=\left(1-S_{M}\right)\left(\frac{\widehat{Y}}{\widehat{L}}\right)^{\delta},
$$

where $S_{M} \in(0,1)$ is the fertiliser share of income, and $\widehat{X}$ denotes the steady-state value of any variable $X_{t}$.

Implicit in the specification of our production function is the assumption that land and physical capital do not enter into the agricultural production process. While this is clearly unrealistic at the microeconomic level, we hold it to be a reasonable modelling choice at the macroeconomic level. In aggregate, land is plausibly not a binding constraint on production in low-income countries, especially in the short-run dynamics with which this work is concerned; and failures in the market for land make it a reasonable simplification to assume this market away. In addition, the financing constraints that apply to purchases or rental of land and physical capital are likely to be similar those that apply to fertiliser purchases, since these inputs need to be acquired well in advance of the harvesting and selling of crops.

Farmers' production is subject to the idiosyncratic shock $\omega_{t}$ which is i.i.d. across time and farms, with a continuous and once-differentiable c.d.f., $\mathcal{F}(\omega)$, over a nonnegative support. Specifically, we assume that $\omega_{t}$ is log-normally distributed, such

\footnotetext{
${ }^{4}$ We are grateful to Giovanni Melina for bringing this approach to our attention.
} 
that

$$
\ln \omega_{t} \sim N\left(-\frac{1}{2} \sigma_{\omega}^{2}, \sigma_{\omega}^{2}\right), \forall t
$$

It follows that $\mathbb{E}_{t-1}\left(\omega_{t}\right)=1, \forall t$.

We interpret the common productivity factor, $A_{t}$, as reflecting weather conditions; we will therefore assume that changes in $A_{t}$ between periods will be large enough to trigger substantial output fluctuations, as will be reflected in our parameterisation. Higher values of our 'weather variable' can be interpreted as more favourable weather conditions. Let $A_{t}$ be determined, relative to its steady-state value $\widehat{A}$, by the stationary $\operatorname{AR}(1)$ process

$$
\ln \left(1+A_{t}\right)-\ln (1+\widehat{A})=\rho^{A}\left[\ln \left(1+A_{t-1}\right)-\ln (1+\widehat{A})\right]+\eta_{t}^{A},
$$

where $\rho^{A} \in(0,1)$ and $\eta_{t}^{A} \sim N\left(0, \sigma_{A}^{2}\right) .^{5}$

At time $t$, the farmer purchases fertiliser for use at time $t+1 .^{6}$ The ex-post gross return to using a unit of fertiliser from $t$ to $t+1$ ('return on fertiliser') for a farm is $\omega_{t+1}\left(1+r_{t+1}^{M}\right)$, where $\left(1+r_{t+1}^{M}\right)$ is the ex-post gross return to fertiliser averaged over farms (which does not depend on realisations of the idiosyncratic shock because $\omega_{t}$ is i.i.d. across farms with mean unity, and the number of farms is large).

\subsubsection{Working capital}

Farmers need 'working capital' to finance their expenditure on fertiliser. We assume that labour is only required at the harvesting stage and does not need paying for in advance, so that no borrowing is required to purchase labour. At the end of period $t$ (going into period $t+1$ ), the farmer has net worth of $N_{t+1}$ available, which is defined as liquid assets plus the collateral value of illiquid assets net of liabilities. In the present model, farmers start off with an exogenously given amount of inherited net worth, and subsequent additions to their net worth come from retained earnings. BGG make their entrepreneur (re)purchase her entire capital stock each period as a modelling device to ensure that financial constraints apply to the firm as a whole and not just to the marginal investment. Here we assume that fertiliser cannot be reused once it has been applied, which is equivalent to assuming a 100\% depreciation rate in a model with capital; it therefore follows trivially that the farmer must purchase her entire fertiliser stock every period.

Fertiliser attracts an ad valorem subsidy at a fixed rate. To be able to purchase fertiliser net of the subsidy in excess of the value of her net worth, the farmer needs (uncollateralised) nominal debt $B_{t+1}$ such that

$$
\frac{B_{t+1}}{P_{t}}=\kappa m_{t} M_{t+1}-N_{t+1}
$$

where $m_{t}$ is the real local-currency price of fertiliser purchased at time $t$, which depends on the world price of fertiliser and the exchange rate (as specified later); $(1-\kappa) \in[0,1)$ is the rate at which fertiliser is subsidised, so that $\kappa \in(0,1]$ is the

\footnotetext{
${ }^{5}$ The weather variable could be given a seasonal component if periods are interpreted as quarters.

${ }^{6} \mathrm{~A}$ possible interpretation could be that the fertiliser must be purchased and dissolved into the ground in period $t$ as the crops are planted, but production is only understood to occur when the crops are harvested in period $t+1$.
} 
proportion of the value of fertiliser not covered by the government subsidy. Farm debt is made up of debt held by domestic households and foreign investors such that

$$
B_{t+1}=B_{t+1}^{H}+B_{t+1}^{F},
$$

where $B_{t+1}^{F}$ is debt held by foreign investors, and all debt is denominated in domestic currency.

Working capital is provided by a financial intermediary, for whom the relevant opportunity cost of funds between periods $t$ and $t+1$ is the economy's ex-ante riskless gross rate of return $\mathbb{E}_{t}\left[\left(1+i_{t}\right) \frac{P_{t}}{P_{t+1}}\right]$. This is the relevant opportunity cost because idiosyncratic credit risk is perfectly diversified away by the intermediary, and the farmers, whom we assume to be risk neutral, absorb any aggregate risk to relieve risk-averse savers from potential losses. In the presence of aggregate risk (as is the case here due to stochastic weather conditions), the borrower guarantees the lender a return that is free of any systematic risk: conditional on the ex-post realisation of $\left(1+r_{t+1}^{M}\right)$, the borrower offers a (state-contingent) non-default payment that guarantees the lender a return equal in expected value to the riskless rate.

\subsubsection{Financial frictions}

We introduce a costly state-verification problem ${ }^{7}$ wherein the financial intermediary must pay an 'auditing cost' to observe an individual farmer's realised production (the farmer observes her own production costlessly), which can be interpreted as reflecting the cost of bankruptcy; these costs are likely to be all the more significant given the weak insolvency frameworks, inefficient courts, etc., which one is likely to encounter in LICs. We therefore set bankruptcy costs in our parameterisation at a substantially higher level than is common in studies of high-income countries, as explained below. Following BGG and GGN, the monitoring cost is assumed to be a fixed proportion $\tau \in(0,1)$ of the realised gross payoff to the farm's fertiliser (to facilitate aggregation), so that the cost of monitoring a farm at time $t+1$ is

$$
\tau \omega_{t+1}\left(1+r_{t+1}^{M}\right) \kappa m_{t} M_{t+1} .
$$

The optimal contract features a gross non-default loan rate, $\bar{R}_{t+1}^{M}$, and a threshold value of the idiosyncratic shock, $\bar{\omega}_{t+1}$, such that for $\omega_{t+1} \geq \bar{\omega}_{t+1}$ the farmer is able to repay the loan at the rate of interest $\bar{R}_{t+1}^{M}$; therefore, $\bar{\omega}_{t+1}$ is given by

$$
\bar{\omega}_{t+1}\left(1+r_{t+1}^{M}\right) \kappa m_{t} M_{t+1}=\bar{R}_{t+1}^{M} \frac{B_{t+1}}{P_{t}} .
$$

Thus, if $\omega_{t+1} \geq \bar{\omega}_{t+1}$, the farmer pays the lender $\bar{R}_{t+1}^{M} \frac{B_{t+1}}{P_{t}}$, and keeps

$$
\omega_{t+1}\left(1+r_{t+1}^{M}\right) \kappa m_{t} M_{t+1}-\bar{R}_{t+1}^{M} \frac{B_{t+1}}{P_{t}} \geq 0
$$

in profit. If $\omega_{t+1}<\bar{\omega}_{t+1}$, the farmer declares bankruptcy and receives nothing, and the lender pays the auditing cost and keeps what is left. Therefore, the intermediary's net recepits in this case are

$$
(1-\tau) \omega_{t+1}\left(1+r_{t+1}^{M}\right) \kappa m_{t} M_{t+1} .
$$

${ }^{7}$ As first studied by Townsend (1979). 
The expected gross return to the lender must at least equal the intermediary's opportunity cost of lending. Therefore, assuming that this constraint binds, the values of $\bar{\omega}_{t+1}$ and $\bar{R}_{t+1}^{M}$ under the optimal contract are given by

$$
\begin{array}{r}
{\left[1-\mathcal{F}\left(\bar{\omega}_{t+1}\right)\right] \bar{R}_{t+1}^{M} \frac{B_{t+1}}{P_{t}}+(1-\tau) \int_{0}^{\bar{\omega}_{t+1}} \omega_{t+1}\left(1+r_{t+1}^{M}\right) \kappa m_{t} M_{t+1} \mathrm{~d} \mathcal{F}\left(\omega_{t+1}\right)} \\
=\left(1+i_{t}\right) \frac{P_{t}}{P_{t+1}} \frac{B_{t+1}}{P_{t}},
\end{array}
$$

where $\mathcal{F}\left(\bar{\omega}_{t+1}\right)$ is the probability of default. Combining equations (14) and (17) with equation (20) gives

$$
\begin{array}{r}
\left\{\left[1-\mathcal{F}\left(\bar{\omega}_{t+1}\right)\right] \bar{\omega}_{t+1}+(1-\tau) \int_{0}^{\bar{\omega}_{t+1}} \omega_{t+1} \mathrm{~d} \mathcal{F}\left(\omega_{t+1}\right)\right\}\left(1+r_{t+1}^{M}\right) \kappa m_{t} M_{t+1} \\
=\left(1+i_{t}\right) \frac{P_{t}}{P_{t+1}}\left(\kappa m_{t} M_{t+1}-N_{t+1}\right) .
\end{array}
$$

Eliminating $\bar{R}_{t+1}^{M}$ allows us to express the lender's expected return simply as a function of the cutoff value of the farm's idiosyncratic productivity shock, $\bar{\omega}_{t+1}$. Under the assumed distribution of the idiosyncratic shock, the expected return reaches a maximum at an unique interior value of $\bar{\omega}_{t+1}$. For simplicity, we restrict attention to equilibria where lending is not rationed, that is, where the equilibrium value of $\bar{\omega}_{t+1}$ is always less than its maximum feasible value.

Given aggregate risk due to stochastic weather conditions, equation (21) implies a set of restrictions, with one for each realisation of the return on fertiliser, resulting in a schedule for $\bar{\omega}_{t+1}$, contingent on macroeconomic conditions. The loan rate $\bar{R}_{t+1}^{M}$ is countercyclical: worse-than-expected weather leads to a higher non-default interest rate to compensate for the greater probability of a default occurring; this in turn implies a higher cutoff value of the idiosyncratic shock, $\bar{\omega}_{t+1}$. Thus, default probabilities and risk premia rise when worse-than-expected macroeconomic conditions are realised.

The farmer's expected return is the expectation of profits in states of the world where the realised idiosyncratic shock is above its cutoff value $\bar{\omega}_{t+1}$, net of loan repayments:

$$
\mathbb{E}_{t}\left\{\int_{\bar{\omega}_{t+1}}^{\infty} \omega_{t+1}\left(1+r_{t+1}^{M}\right) \kappa m_{t} M_{t+1} \mathrm{~d} \mathcal{F}\left(\omega_{t+1}\right)-\left[1-\mathcal{F}\left(\bar{\omega}_{t+1}\right)\right] \bar{R}_{t+1}^{M} \frac{B_{t+1}}{P_{t}}\right\}
$$

which equals

$\mathbb{E}_{t}\left\{\int_{\bar{\omega}_{t+1}}^{\infty} \omega_{t+1}\left(1+r_{t+1}^{M}\right) \kappa m_{t} M_{t+1} \mathrm{~d} \mathcal{F}\left(\omega_{t+1}\right)-\left[1-\mathcal{F}\left(\bar{\omega}_{t+1}\right)\right] \bar{\omega}_{t+1}\left(1+r_{t+1}^{M}\right) \kappa m_{t} M_{t+1}\right\}$,

and where it is understood that $\bar{\omega}_{t+1}$ may be made contingent on the realisation of the aggregate return on fertiliser at $t+1$. It follows from equation (21) that

$$
\begin{aligned}
& {\left[1-\mathcal{F}\left(\bar{\omega}_{t+1}\right)\right] \bar{\omega}_{t+1}\left(1+r_{t+1}^{M}\right) \kappa m_{t} M_{t+1}=-\int_{0}^{\bar{\omega}_{t+1}} \omega_{t+1}\left(1+r_{t+1}^{M}\right) \kappa m_{t} M_{t+1} \mathrm{~d} \mathcal{F}\left(\omega_{t+1}\right)} \\
& \quad+\tau \int_{0}^{\bar{\omega}_{t+1}} \omega_{t+1}\left(1+r_{t+1}^{M}\right) \kappa m_{t} M_{t+1} \mathrm{~d} \mathcal{F}\left(\omega_{t+1}\right)+\left(1+i_{t}\right) \frac{P_{t}}{P_{t+1}}\left(\kappa m_{t} M_{t+1}-N_{t+1}\right)
\end{aligned}
$$


which we can substitute into expression (23) to give the following expression for the farmer's expected return:

$$
\mathbb{E}_{t}\left[\int_{\bar{\omega}_{t+1}}^{\infty} \omega_{t+1}\left(1+r_{t+1}^{M}\right) \kappa m_{t} M_{t+1} \mathrm{~d} \mathcal{F}\left(\omega_{t+1}\right)\right]-\mathbb{E}_{t}[\cdot],
$$

where $\mathbb{E}_{t}[\cdot]$ is the expected value of the right-hand side of equation (24). Rearranging expression (25) gives

$$
\begin{array}{r}
\mathbb{E}_{t}\left\{\left[1-\tau \int_{0}^{\bar{\omega}_{t+1}} \omega_{t+1} \mathrm{~d} \mathcal{F}\left(\omega_{t+1}\right)\right] U_{t+1}^{r M}\right\} \mathbb{E}_{t}\left[\left(1+r_{t+1}^{M}\right)\right] \kappa m_{t} M_{t+1} \\
-\mathbb{E}_{t}\left[\left(1+i_{t}\right) \frac{P_{t}}{P_{t+1}}\left(\kappa m_{t} M_{t+1}-N_{t+1}\right)\right],
\end{array}
$$

as the expression which the farmer seeks to maximise, where

$$
U_{t+1}^{r M} \equiv\left(1+r_{t+1}^{M}\right) / \mathbb{E}_{t}\left[1+r_{t+1}^{M}\right] .
$$

The problem is then to choose $M_{t+1}$ and a schedule for $\bar{\omega}_{t+1}$ (as a function of realised weather) to maximise expression (26), subject to the set of state-contingent constraints implied by equation (21).

\subsubsection{Net worth and demand for fertiliser}

For farmers to be willing to purchase fertiliser in the competitive equilibrium, a necessary condition is that

$$
s_{t} \equiv \mathbb{E}_{t}\left[\frac{1+r_{t+1}^{M}}{\left(1+i_{t}\right) \frac{P_{t}}{P_{t+1}}}\right] \geq 1,
$$

that is, the expected gross discounted return to fertiliser must be at least unity. The variable $s_{t}$ can also be interpreted as the EFP. Indeed, in equilibrium farmers will equate the discounted marginal return to fertiliser to the marginal cost of external finance; if $s_{t}$ is strictly greater than unity, there is a 'wedge' between the cost of external finance and the risk-free rate. Given $s_{t} \geq 1$, the first-order conditions imply that optimal fertiliser purchases satisfy

$$
\kappa m_{t} M_{t+1}=\chi\left(s_{t}\right) N_{t+1}
$$

where $\chi(\cdot)$ is a strictly increasing function with $\chi(1)=1$. This relation shows that fertiliser purchases by each farm are proportional to the farmer's net worth, and the proportionality factor is increasing in the expected discounted return to fertiliser, $s_{t}$. Ceteris paribus, a rise in the expected discounted return to fertiliser reduces the expected default probability; therefore, the farmer can borrow more and increase the size of her farm, within the constraints imposed by the fact that expected default costs increase as leverage (the ratio of total assets to net worth) increases. Rearranging equation (29) as

$$
\frac{\kappa m_{t} M_{t+1}}{N_{t+1}}=\chi\left(s_{t}\right)
$$

shows the positive relation between leverage, which is the left-hand side of equation (30), and the EFP. 
Higher leverage drives further apart the interests of the borrower and the lender. For a given amount of total assets, a lower proportion of equity (net worth) and a correspondingly higher proportion of debt mean that the farmer has less to lose if her venture turns out to be unprofitable. Therefore, at least from the point of view of the lender, a more highly leveraged borrower carries a higher risk of default amid information asymmetries between lender and borrower, other things being equal. In the context of a high- or middle-income country, a possible explanation would be that higher leverage leads borrowers to take on higher-risk projects, since they would stand to make a higher return on equity on the upside, while having less to lose on the downside. In a low-income country, it seems more plausible to assume that a more highly leveraged farmer has a lesser incentive to exercise 'due care' or exert 'appropriate effort'. This explains the negative relationship between net worth and the EFP. Procyclical net worth thus leads to a countercyclical EFP, so that financial frictions magnify economic downturns by increasing the cost of external funds: this is the 'financial accelerator' introduced by Bernanke et al. (1996).

The farmer's demand for fertiliser satisfies the optimality condition

$$
\mathbb{E}_{t}\left[1+r_{t+1}^{M}\right]=\left[1+\chi_{t}(\cdot)\right] \mathbb{E}_{t}\left[\left(1+i_{t}\right) \frac{P_{t}}{P_{t+1}}\right]
$$

where $\mathbb{E}_{t}\left[\left(1+i_{t}\right) \frac{P_{t}}{P_{t+1}}\right]$ would be the (expected) gross cost of funds in the absence of financial frictions; we denote this term $\left(1+r_{t+1}\right)$ for simulation purposes.

Given that the production function $Y_{t}$ is CRS, we can write the production function as an aggregate relationship. Let $P_{W, t}^{Y}$ denote the nominal price index for domestic wholesale output ${ }^{8}$ (in domestic currency), so that $P_{W, t}^{Y} / P_{t}$ is the real price of wholesale output. We continue to assume that fertiliser must be purchased at the end of one period for use in the following period, so that $\kappa m_{t-1}$ is the cost of fertiliser that is used in period $t$. The (risk-neutral) farmers choose fertiliser and labour inputs, for given production and factor prices, to maximise the expected value of

$$
\frac{P_{W, t}^{Y}}{P_{t}} A_{t}\left[\alpha_{M} M_{t}^{\delta}+\alpha_{L} L_{t}^{\delta}\right]^{1 / \delta}-\kappa m_{t-1} M_{t}-\frac{W_{t}}{P_{t}} L_{t} .
$$

The first-order condition with respect to fertiliser is

$$
\frac{P_{W, t}^{Y}}{P_{t}} A_{t} \frac{1}{\delta} \delta \alpha_{M} M_{t}^{\delta-1}\left[\alpha_{M} M_{t}^{\delta}+\alpha_{L} L_{t}^{\delta}\right]^{(1-\delta) / \delta}-\kappa m_{t-1}=0 .
$$

It follows that

$$
\frac{P_{W, t}^{Y}}{P_{t}} \alpha_{M} M_{t}^{\delta-1} A_{t}[\cdot]^{(1-\delta) / \delta}=\kappa m_{t-1}
$$

Given that

$$
Y_{t}=A_{t}[\cdot]^{1 / \delta}
$$

we have

$$
[\cdot]=\left(\frac{Y_{t}}{A_{t}}\right)^{\delta}
$$

\footnotetext{
${ }^{8}$ In a sense explained below.
} 
and therefore

$$
A_{t}[\cdot]^{(1-\delta) / \delta}=A_{t}^{\delta} Y_{t}^{1-\delta}
$$

It follows that

$$
\frac{P_{W, t}^{Y}}{P_{t}} \alpha_{M} M_{t}^{\delta-1} A_{t}^{\delta} Y_{t}^{1-\delta}=\kappa m_{t-1}
$$

and hence

$$
M_{t}^{\delta-1}=\left(\frac{\alpha_{M} P_{W, t}^{Y}}{P_{t} \kappa m_{t-1}}\right)^{-1} A_{t}^{-\delta} Y_{t}^{\delta-1}
$$

Since the elasticity of substitution is $\Sigma=1 /(1-\delta)$, we therefore obtain

$$
M_{t}=\left(\frac{\alpha_{M} P_{W, t}^{Y}}{P_{t} \kappa m_{t-1}}\right)^{\Sigma} A_{t}^{\Sigma-1} Y_{t}
$$

as the amount of fertiliser used for a given desired production level $Y_{t}$. Similarly,

$$
L_{t}=\left\{\frac{\left[\alpha_{L} P_{W, t}^{Y}\right] / P_{t}}{W_{t} / P_{t}}\right\}^{\Sigma} A_{t}^{\Sigma-1} Y_{t},
$$

giving

$$
L_{t}=\left[\frac{\alpha_{L} P_{W, t}^{Y}}{W_{t}}\right]^{\Sigma} A_{t}^{\Sigma-1} Y_{t}
$$

Farmers are assumed to produce in a perfectly competitive market for wholesale goods, to facilitate aggregation. We introduce 'nominal stickiness' in a later section by assuming that farmers sell their (wholesale) production to retail firms which operate in a monopolistically competitive market for final goods.

The rent paid to a unit of fertiliser, in terms of retail prices, is

$$
\frac{P_{W, t}^{Y}}{P_{t}} \alpha_{M} A_{t}^{(\Sigma-1) / \Sigma}\left(\frac{Y_{t}}{M_{t}}\right)^{1 / \Sigma}
$$

and the expected gross return to using a unit of fertiliser from $t$ to $t+1$ can then be written as

$$
\mathbb{E}_{t}\left[1+r_{t+1}^{M}\right]=\frac{1}{\kappa m_{t}} \mathbb{E}_{t}\left[\frac{P_{W, t+1}^{Y}}{P_{t+1}} \alpha_{M} A_{t+1}^{(\Sigma-1) / \Sigma}\left(\frac{Y_{t+1}}{M_{t+1}}\right)^{1 / \Sigma}\right],
$$

noting that this is both the marginal and the average return to fertiliser given constant returns to scale. This gives a demand function for fertiliser.

To obtain a supply function for finance, we aggregate equation (29) over farms and invert $\chi(\cdot)$, which yields

$$
\mathbb{E}_{t}\left[1+r_{t+1}^{M}\right]=s\left(\frac{N_{t+1}}{\kappa m_{t} M_{t+1}}\right) \mathbb{E}_{t}\left[\left(1+i_{t}\right) \frac{P_{t}}{P_{t+1}}\right],
$$


where $s(\cdot)$ is a decreasing function for $N_{t+1}<\kappa m_{t} M_{t+1}$; it is also the ratio of the costs of external and internal finance, and this ratio is clearly increasing in the farmer's leverage. Appendix 1 outlines the derivation of the financial accelerator equations which appear in our model.

To avoid the possibility that farmers become self-financing, we must assume that they have a finite expected horizon. Each farmer survives until the next period with probability $\eta$. Every farmer who dies is replaced by a new entrant, so that the population of farmers is constant. To have some initial net worth to set up their farm, the new farmers receive a constant small bequest $\zeta$ from the accumulated wealth of the dying farmers; the remainder of the latter group's estate is collected by the government as inheritance tax. Let $V_{t}$ be farmers' aggregate retained earnings (that is, the wealth which they have accumulated from farming activities); then, $\eta V_{t}$ is the amount retained by surviving farmers. Farmers' aggregate net worth at the end of period $t, N_{t+1}$, then evolves according to

$$
N_{t+1}=\eta V_{t}+\zeta
$$

and the amount collected from the dying farmers by the government is $(1-\eta) V_{t}-\zeta .^{9}$ Aggregate retained earnings are given by

$$
V_{t}=\left(1+r_{t}^{M}\right) \kappa m_{t-1} M_{t}-\left(1+i_{t-1}\right) \frac{B_{t}}{P_{t}}-\tau \int_{0}^{\bar{\omega}_{t}} \omega_{t}\left(1+r_{t}^{M}\right) \kappa m_{t-1} M_{t} \mathrm{~d} \mathcal{F}\left(\omega_{t}\right),
$$

that is, the aggregate return on fertiliser net of interest repayments and funds lost in bankruptcy.

\subsection{Wholesale prices}

A limitation of the GGN model arises from the assumptions that the law of one price holds at the wholesale level and that the world wholesale price is determined exogenously. This implies that the domestic nominal price of wholesale goods is entirely determined by the exogenous world price and by the nominal exchange rate, and does not respond to the production costs of domestic firms. Price stickiness aside, domestic and foreign retail prices are simply given by a markup over the wholesale prices; the upshot is that domestic inflation is in turn entirely determined by exogenous world wholesale prices and by the nominal exchange rate.

To enable domestic wholesale (and retail) prices to depend on domestic conditions, we must distinguish between non-traded goods sold to the domestic market $\left(C_{t}^{H}\right)$ and traded goods destined for the export market $\left(C_{t}^{X}\right)$. Let $Q_{t}$ be composite domestic output consumed by households at home and abroad, and be given by

$$
Q_{t}=\psi\left[\alpha\left(C_{t}^{H}\right)^{(\sigma+1) / \sigma}+(1-\alpha)\left(C_{t}^{X}\right)^{(\sigma+1) / \sigma}\right]^{\sigma /(\sigma+1)},
$$

where $\psi$ is a scaling parameter, $\alpha \in(0,1)$ is a share parameter, and the elasticity of transformation $0<\sigma<\infty$ represents the cost of switching production between markets. Output can be sold to the domestic market at wholesale price $P_{W, t}^{H}$ or exported at wholesale price $P_{W, t}^{X}$. The farmer chooses $C_{t}^{H}$ and $C_{t}^{X}$ to maximise revenue

$$
P_{W, t}^{H} C_{t}^{H}+P_{W, t}^{X} C_{t}^{X}
$$

${ }^{9}$ Note that this is technically equivalent to assuming that the government collects the entire accumulated wealth of dying farmers and itself makes a constant transfer to the new farmers. 
subject to equation (48), which gives the first-order condition:

$$
\frac{C_{t}^{X}}{C_{t}^{H}}=\left[\left(\frac{\alpha}{1-\alpha}\right)\left(\frac{P_{W, t}^{X}}{P_{W, t}^{H}}\right)\right]^{\sigma}
$$

We define $P_{W, t}^{Q}$ as the wholesale price of the composite $Q_{t}$, which is then given by

$$
P_{W, t}^{Q}=\frac{P_{W, t}^{H} C_{t}^{H}+P_{W, t}^{X} C_{t}^{X}}{Q_{t}} .
$$

We assume that government consumption, $G$, is composed entirely of domestic output bought directly from producers, so that the price applicable to it is $P_{W, t}^{H}$. A portion of output is 'consumed' by monitoring costs, and we assume that this is valued with the same price index as $Y_{t}$. The (wholesale) price index for $Y_{t}$ is then given by

$$
P_{W, t}^{Y}=\frac{P_{W, t}^{Q} Q_{t}+P_{W, t}^{H} G+P_{W, t}^{Y} \tau \int_{0}^{\bar{\omega}_{t}} \omega_{t}\left(1+r_{t}^{M}\right) \kappa m_{t-1} M_{t} \mathrm{~d} \mathcal{F}\left(\omega_{t}\right)}{Y_{t}}
$$

Let $S_{t}$ be the nominal exchange rate defined in units of domestic currency per unit of foreign currency, so that an increase in $S_{t}$ is a depreciation of the domestic currency. With $P_{W, t}^{X}$ and $P_{W, t}^{X *}$ the price of exported wholesale goods in domestic and foreign currency respectively, we have $P_{W, t}^{X}=S_{t} P_{W, t}^{X *}$ and normalising $P_{W, t}^{X *}$ to unity gives

$$
P_{W, t}^{X}=S_{t}
$$

\subsection{Retailers, price setting, and inflation}

There is a continuum of domestic retail firms of measure one, with each such firm indexed by $z$. Retail firms purchase domestic wholesale goods in a perfectly competitive market, and differentiate them at a fixed resource cost $\xi$ which represents distribution and selling costs. Let $C_{t}^{H}(z)$ be the good sold by retailer $z$. Then, total domestic goods consumed at home is given by a CES composite of individual retail goods:

$$
C_{t}^{H}=\left\{\int_{0}^{1}\left[C_{t}^{H}(z)\right]^{(\vartheta-1) / \vartheta} \mathrm{d} z\right\}^{\vartheta /(\vartheta-1)}-\xi,
$$

where $\vartheta>1$. The corresponding price index is

$$
P_{R, t}^{H}=\left\{\int_{0}^{1}\left[P_{R, t}^{H}(z)\right]^{1-\vartheta} \mathrm{d} z\right\}^{1 /(1-\vartheta)} .
$$

It follows that the demand curve facing retailer $z$ is given by

$$
C_{t}^{H}(z)=\left[\frac{P_{R, t}^{H}(z)}{P_{R, t}^{H}}\right]^{-\vartheta} C_{t}^{H}
$$

The marginal cost to retailers of producing a unit of output is the relative wholesale price of goods destined for the domestic market, $P_{W, t}^{H} / P_{R, t}^{H}$. We assume Calvo (1983) 
pricing, with each retailer able to change her price with constant probability $(1-\theta)$ in any period, so that in each period a fraction $(1-\theta)$ of retailers reset their price while a fraction $\theta \in(0,1)$ keep their prices unchanged. The average time that a price remains fixed is then $1 /(1-\theta)$. Since there are no firm-specific state variables, all retailers choose the same optimal price $\bar{P}_{R, t}^{H}$. It can be shown that, in the neighbourhood of the steady state, the domestic price index evolves according to

$$
P_{R, t}^{H}=\left(P_{R, t-1}^{H}\right)^{\theta}\left(\bar{P}_{R, t}^{H}\right)^{1-\theta} .
$$

Retailers able to set their prices in a given period do so to maximise expected discounted profits, subject to the constraint on the frequency of price adjustments. It can be shown that, within a local neighbourhood of the steady state, the optimal price is

$$
\bar{P}_{R, t}^{H}=\mu \prod_{i=0}^{\infty}\left(P_{W, t+i}^{H}\right)^{(1-\beta \theta)(\beta \theta)^{i}}
$$

where

$$
\mu=\frac{1}{1-1 / \vartheta}
$$

is the retailers' desired gross markup over wholesale prices. In the steady state, $\mu$ is the actual gross markup over wholesale prices, so that $\mu=\widehat{P_{R}^{H} / P_{W}^{H}}$. However, because prices may be fixed for some time, retailers set prices based on the expected future path of the marginal cost. Combining equations (57) and (58) above gives the following expression for the change in the price of domestically produced goods (within the neighbourhood of a zero-inflation steady state):

$$
\frac{P_{R, t}^{H}}{P_{R, t-1}^{H}}=\left(\mu \frac{P_{W, t}^{H}}{P_{R, t}^{H}}\right)^{\lambda_{p}} \mathbb{E}_{t}\left(\frac{P_{R, t+1}^{H}}{P_{R, t}^{H}}\right)^{\beta},
$$

where $\lambda_{p}=\frac{(1-\theta)(1-\beta \theta)}{\theta}$ is a parameter reflecting the sensitivity of the price of domestic retail goods to the marginal cost of 'production'. This is a 'Phillips curve' (for domestically produced goods alone) closely related to the 'standard' New-Keynesian Phillips curve (NKPC), which describes a positive relationship between current inflation on the one hand and expected future inflation and the output gap on the other hand. This 'Phillips curve' replaces the output gap term with a marginal cost term, given by the relative wholesale price, as suggested by Galí and Gertler (1999). These authors consider using measures of marginal costs as the relevant determinant of inflation to be more consistent with economic theory than an ad-hoc output gap. They also find this version of the NKPC to be a good first-approximation to the dynamics of inflation (for US data), unlike the 'standard' NKPC.

With $P_{W, t}^{M}$ and $P_{W, t}^{M *}$ the price of imported wholesale goods in domestic and foreign currency respectively, we have $P_{W, t}^{M}=S_{t} P_{W, t}^{M *}$, where $P_{W, t}^{M *}$ is determined exogenously. We normalise $P_{W, t}^{M *}$ to 1 , so $P_{W, t}^{M}=S_{t}$. For simplicity, we assume that foreign retail prices are a proportional markup over their wholesale price, so the foreign currency price of imported retail goods is then $P_{R, t}^{M *}=\mu^{f}$, and we therefore obtain

$$
P_{R, t}^{M}=\mu^{f} S_{t}
$$


Domestic CPI inflation is a composite of domestic and foreign good price inflation, and is given by (within a local region of the steady state):

$$
\frac{P_{t}}{P_{t-1}}=\left(\frac{P_{R, t}^{H}}{P_{R, t-1}^{H}}\right)^{\gamma}\left(\frac{P_{R, t}^{M}}{P_{R, t-1}^{M}}\right)^{1-\gamma} .
$$

\subsection{Real exchange rate and cost of fertiliser}

The real exchange rate, in units of imported retail goods per unit of domestic retail goods, is given by

$$
e_{t}=\frac{S_{t} P_{R, t}^{M *}}{P_{R, t}^{H}},
$$

which, after our normalisation, becomes

$$
e_{t}=\frac{S_{t} \mu^{f}}{P_{R, t}^{H}} .
$$

Let $m_{t}^{*}$ be the real foreign-currency price of fertiliser, which is related to the real domestic-currency CPI price of fertiliser $\left(m_{t}\right)$ by

$$
m_{t}=\frac{S_{t}}{P_{t}} m_{t}^{*}
$$

The real price of fertiliser in foreign currency, $m_{t}^{*}$, is determined, relative to its steady-state value $\widehat{m}^{*}$, by the stationary $\operatorname{AR}(1)$ process:

$$
\ln \left(1+m_{t}^{*}\right)-\ln \left(1+\widehat{m}^{*}\right)=\rho^{m^{*}}\left[\ln \left(1+m_{t-1}^{*}\right)-\ln \left(1+\widehat{m}^{*}\right)\right]+\eta_{t}^{m^{*}},
$$

where $\rho^{m^{*}} \in(0,1)$ and $\eta_{t}^{m^{*}} \sim N\left(0, \sigma_{m^{*}}^{2}\right)$.

\subsection{Government budget constraint}

The government spends its funds on fertiliser subsidies and on domestic goods for its own consumption, $G$, measured in real terms, which is assumed to be fixed. Government expenditure is financed solely by inheritance taxes and real net budgetary aid $a_{t}$ (in foreign currency terms); the latter adjusts automatically to satisfy the government budget constraint. The budget constraint faced by the government, in real terms, is therefore:

$$
\frac{P_{W, t}^{H}}{P_{R, t}^{H}} G+(1-\kappa) \frac{S_{t} m_{t}^{*}}{P_{R, t}^{H}} M_{t+1}=e_{t} a_{t}+(1-\eta) V_{t}-\zeta .
$$

The first term on the left-hand side (LHS) represents real government consumption; the second term on the LHS is real expenditure on fertiliser subsidies; the first term on the right-hand side (RHS) represents real net budgetary aid in domestic currency terms; and the remainder of the RHS represents inheritance tax receipts.

\subsection{Resource constraint}

The resource constraint for the economy is

$$
Y_{t}=Q_{t}+G+\tau \int_{0}^{\bar{\omega}_{t}} \omega_{t}\left(1+r_{t}^{M}\right) \kappa m_{t-1} M_{t} \mathrm{~d} \mathcal{F}\left(\omega_{t}\right)+\xi,
$$

where the $\tau \ldots$ term represents aggregate monitoring costs. 


\subsection{Balance of payments}

Following Adam et al. (2008), the supply of funds by foreign investors is given implicitly by the arbitrage condition

$$
\mathbb{E}_{t}\left[\left(1+i_{t}\right) \frac{P_{t}}{P_{t+1}}\right]=\mathbb{E}_{t}\left[1+r^{*}\right]\left(\frac{\mathbb{E}_{t}\left[e_{t+1}\right]}{e_{t}}\right)^{\gamma} \phi\left(\frac{B_{t}^{F} / P_{t}}{Y_{t}}\right),
$$

where $r^{*}$ is the exogenous world real interest rate (assumed fixed), and $\phi>0$ is a parameter denoting the slope of the schedule for the supply of funds from abroad. The $\phi(\cdot)$ term corresponds to the risk premium, since the (foreign) investors need a higher yield to compensate them for the greater risk in lending to domestic firms which comes with an increased foreign-debt-to-GDP ratio. As $\phi \longrightarrow 0$, the arbitrage condition reduces to the uncovered interest parity condition which obtains amid perfect asset substitutability. As $\phi \longrightarrow \infty$ foreign investors demand an infinite risk premium, and the home country can no longer borrow from abroad, resulting in a closed capital account. The intermediate case we consider, where $\phi$ is strictly positive and finite, corresponds to the case in which the capital account is 'imperfectly open', as is common in much of Sub-Saharan Africa (Adam et al., 2008).

The balance of payments equation, in terms of world wholesale prices, is given by

$$
P_{W, t}^{M *} a_{t}+P_{W, t}^{M *} C_{t}^{X}+\frac{\Delta B_{t+1}^{F}}{S_{t}}=P_{W, t}^{M *} C_{t}^{M}+m_{t}^{*} M_{t}+\frac{i_{t-1} B_{t}^{F}}{S_{t}},
$$

where the LHS terms are inflows, and the RHS terms are outflows.

\subsection{Policy rules}

The domestic CPI inflation rate, $\pi_{t}$, is given by

$$
1+\pi_{t}=\frac{P_{t}}{P_{t-1}} .
$$

For simplicity, we follow GGN in assuming that the central bank is able credibly to commit to following the interest rate rule (IRR), so that the inflation target is achieved in the steady state. ${ }^{10}$ Monetary-policy makers respond to shocks by following an IRR, given in its most general form by:

$$
\frac{1+i_{t}}{1+\widehat{r}}=\left(\frac{1+i_{t-1}}{1+\widehat{r}}\right)^{\gamma_{i}}\left(\frac{1+\mathbb{E}_{t}\left[\pi_{t+1}\right]}{1+\pi^{\Theta}}\right)^{\gamma_{E \pi}}\left(\frac{1+\pi_{t}}{1+\pi^{\Theta}}\right)^{\gamma_{\pi}}\left(\frac{Y_{t}}{Y^{\Theta}}\right)^{\gamma_{y}}\left(\frac{S_{t}}{S^{\Theta}}\right)^{\gamma_{S}},
$$

where $\widehat{r}$ is the steady-state real interest rate, $\pi^{\Theta}$ is the inflation target, $Y^{\Theta}$ is the output target, and $S^{\Theta}$ is the nominal exchange rate target (note that an increase in $S_{t}$ is a domestic depreciation). Parameters $\gamma_{E \pi}, \gamma_{\pi}, \gamma_{y}$, and $\gamma_{S}$ indicate the degree to which monetary-policy makers adjust the nominal interest rate in response to deviations of the variables from their respective targets, and are all greater than or equal to zero. The parameter $\gamma_{i} \in[0,1]$ is set to 0 if there is no interest-rate smoothing objective, and is strictly positive otherwise.

\footnotetext{
${ }^{10}$ Assuming away the possibility of inflation bias is not meant as an approximation of reality in our case, but rather as a characterisation of outcomes under a desirable policy rule.
} 
If $\gamma_{\pi}>0, \gamma_{y}>0$, and $\gamma_{i}=\gamma_{E \pi}=\gamma_{S}=0$, the IRR collapses to a standard Taylor (1993)-type rule, as used by GGN. In this case, we interpret the rule to be a form of flexible inflation targeting, or 'constrained discretion', so that the central bank adjusts the interest rate to achieve the inflation target in the medium run, while enjoying flexibility in the short run to meet output stabilisation objectives. If $\gamma_{E \pi}>0$, the central bank sets interest rates based on forecast inflation, amongst other variables, and if $\gamma_{S}>0$ the central bank also manages the nominal exchange rate. In the extreme case where the central bank simply fixes the nominal exchange rate, the interest rate rule is replaced by

$$
S_{t}=S^{\Theta}
$$

In our baseline analysis, the fertiliser subsidy rate is fixed at $(1-\kappa)$. In one of our experiments we introduce an endogenous subsidy rate which stabilises the cost of fertiliser to domestic farmers. The subsidy rate becomes $\left(1-\kappa_{t}\right)$, where

$$
\kappa_{t}=\kappa\left(\frac{\widehat{m}}{m_{t}}\right)^{\Omega},
$$

with $\Omega>0$. The subsidy then rises above its baseline rate as the domestic fertiliser price rises above its steady-state value.

\section{Baseline parameterisation}

The quarterly discount factor, $\beta$, is set to achieve a value of the steady-state quarterly real interest rate of approximately $5 \%$; this is consistent with recent World Bank data for the lending rate in Kenya adjusted for the GDP deflator. The value for $\widehat{r^{*}}$ is taken from Buffie et al. (2012). The magnitudes for $\widehat{C / Y}, \widehat{C^{M} / Y}$, and $\widehat{C^{X} / Y}$ are also obtained from recent World Bank data for Kenya, with balanced trade imposed in the steady state $\left(\right.$ i.e., $\widehat{C^{M} / Y}=\widehat{C^{X} / Y}$ ). We are not aware of empirical estimates of the parameters $\mu$ or $\sigma_{\omega}^{2}$ for Kenya or other LICs, so these values are taken from GGN, although Dobrinsky et al. (2006) estimate similar values of $\mu$ for Bulgaria and Hungary; accordingly, we set the retailers' fixed resource cost, $\xi$, to 0.2 so that retailers' profits are zero in the steady state. Values of $\nu, \rho$, and $\widehat{B^{F} / B^{H}}$ are from Adam et al. (2008); the relatively low value of the intertemporal elasticity of substitution, $1 / \nu$, is consistent with the notion that low-income households, which also tend to have limited access to formal financial services, may find it relatively difficult to smooth consumption (and leisure) over time. The value of the elasticity of transformation between goods destined for the domestic and export markets, $\sigma$, corresponds to a relatively sluggish adjustment of the composition of production in response to change in the relative price.

The elasticity of substitution between the two factors of production, $\Sigma$, is set at 0.4 following León-Ledesma et al. (2010), which is at the lower end of US estimates (for labour and capital) surveyed in León-Ledesma et al. (2015). Our choice is consistent with Islam and Islam's (2010) study of rice production in Bangladesh, which finds elasticities of substitution between labour and fertiliser ranging from 0.09 to 0.98. In light of the discussion of fertiliser subsidies in Section 2, we set $\kappa$ so that the subsidy rate is $20 \%$. Given weak insolvency frameworks in LICs, the proportion of realised payoffs lost in bankruptcy is likely to be especially high. GGN 
set $\tau$ to 0.12 , while estimates surveyed by Carlstrom and Fuerst (1997) go up to

0.36 for the US, and Aysun (2008) finds 0.5 to be a reasonable estimate for Brazil.

\section{Table 1. Baseline parameterisation values}

\begin{tabular}{|c|c|c|}
\hline$\beta$ & 0.95 & Quarterly discount factor \\
\hline$\widehat{B^{F} / B^{H}}$ & $1 / 8$ & Ratio of debt held abroad to debt held at home \\
\hline$\widehat{C / Y}$ & 0.75 & Steady-state ratio of consumption to GDP \\
\hline$\widehat{C^{M} / Y}$ & 0.3 & Steady-state ratio of imported retail goods to GDP \\
\hline$\widehat{C^{X} / Y}$ & 0.3 & Steady-state ratio of exported wholesale goods to GDP \\
\hline$\eta$ & 0.85 & Farmer survival rate \\
\hline$\kappa$ & 0.8 & Proportion of fertiliser cost not subsidised \\
\hline$\widehat{L}$ & $1 / 3$ & Steady-state labour employed \\
\hline$\mu$ & 1.2 & Domestic retailers' steady-state markup over wholesale prices \\
\hline$\nu$ & 2 & Inverse of intertemporal elasticity of substitution \\
\hline$\Omega$ & 0.5 & Sensitivity of endogenous fertiliser subsidy to fertiliser price \\
\hline$\pi^{\Theta}$ & $\widehat{\pi}=0$ & Inflation target \\
\hline$\widehat{r^{*}}$ & 0.04 & Steady-state world real interest rate \\
\hline$\rho$ & 0.5 & Domestic/imported retail good elasticity of substitution \\
\hline$S_{M}$ & 0.25 & Fertiliser share of national income \\
\hline$S^{\Theta}$ & $\widehat{S}=1$ & Nominal exchange rate target \\
\hline$\Sigma$ & 0.4 & Fertiliser/labour elasticity of substitution \\
\hline$\sigma$ & 0.75 & Domestic/export market elasticity of transformation \\
\hline$\sigma_{\omega}^{2}$ & 0.28 & Variance of idiosyncratic shock \\
\hline$\tau$ & 0.65 & 'Monitoring cost' paid in case of farm bankruptcy \\
\hline$\theta$ & 0.5 & Quarterly probability of price not changing (domestic firms) \\
\hline$\xi$ & 0.2 & Retailers' fixed resource cost \\
\hline$Y^{\Theta}$ & $\widehat{Y}=1$ & Output target \\
\hline$\rho^{A}$ & 0.95 & Persistence of total factor productivity (weather) \\
\hline$\rho^{m *}$ & 0.95 & Persistence of world real fertiliser price \\
\hline$\gamma_{i}$ & 0 & Interest rate smoothing weight in interest rate rule \\
\hline$\gamma_{E \pi}$ & 0 & Expected-inflation weight in interest rate rule \\
\hline$\gamma_{\pi}$ & 2.00 & Inflation weight in interest rate rule \\
\hline$\gamma_{S}$ & 0 & Nominal exchange rate weight in interest rate rule \\
\hline$\gamma_{y}$ & 1 & Output weight in interest rate rule \\
\hline
\end{tabular}

Duflo et al. (2011) provide estimates for the return to fertiliser in Kenya, with an annualised return of $52 \%$ likely to be a lower bound according to the authors; this is equivalent to a quarterly return of about $17 \%$, and we set the remaining parameters which determine the external finance premium to achieve this rate of return in the steady state. Given the high value of the return on fertiliser (compared to values 
assumed for the return on capital in studies on higher-income countries), we must set the survival rate of farmers, $\eta$, at the relatively low rate of $85 \%$ to ensure that the model satisfies the usual stability conditions when the financial accelerator is 'switched off'. 11

Buffie et al. (2013) survey estimates of the Calvo parameter $\theta$ for less-developed countries and opt for a value of 0.5 , while allowing for alternative values ranging from 0.25 to 0.75 . We set fertiliser's share of national income at a conservative 0.25. In the steady state, GDP and the nominal exchange rate are normalised to 1, and the inflation rate is normalised to 0 ; we assume that the monetary authorities target the steady-state values of these variables, if at all. ${ }^{12}$ We consider highly persistent shocks to total factor productivity and to the world fertiliser price, and therefore set $\rho^{A}$ and $\rho^{m *}$ to 0.95 .

The parameters which have a quantitatively important effect on the variables in the model are the elasticity of substitution between fertiliser and labour, the fertiliser share of national income, the Calvo price-stickiness parameter, and the fertiliser subsidy rate. Other parameters have a significant effect mainly on variables which they affect 'directly', such as the bankruptcy cost parameter on the external finance premium or the elasticity of substitution between domestic and foreign goods on foreign consumption of domestic goods, but not on the overall dynamics of the model. We compared policy responses under alternative values of these parameters, as a robustness check, and the general conclusions of our analysis were unaffected.

\section{$5 \quad$ Results and policy analysis}

\subsection{Baseline results}

Our baseline analysis is conducted using the IRR in GGN with similar monetary policy parameters, that is,

$$
\frac{1+i_{t}}{1+\widehat{r}}=\left(\frac{1+\pi_{t}}{1+\pi^{\Theta}}\right)^{\gamma_{\pi}}\left(\frac{Y_{t}}{Y^{\Theta}}\right)^{\gamma_{y}}
$$

where $\gamma_{\pi}=2$ and $\gamma_{y}=1$. The main variables of interest are plotted in the following figures, where $D x_{t}$ is the percentage deviation of variable $x_{t}$ from its steady state. Thus, $D x_{t}=0$ indicates that $x_{t}$ is at its steady state, while $D x_{t}=0.02$ indicates that $x_{t}$ is $2 \%$ above its steady-state value. Inflation is the only variable equal to zero in the steady state, so we define $D \pi_{t}=\pi_{t}$ for uniformity of notation in the figures, with $D \pi_{t}=0.02$ indicating that $\pi_{t}$ is two percentage points above its steady-state value (which is 0 ).

We first consider the economy's response to a persistent negative two-percent shock to total factor productivity $\left(A_{t}\right)$, which we interpret as an ongoing adverse weather shock (e.g., a drought). Impulse response functions (IRFs) are plotted in Figures $1 \mathrm{a}$ and $1 \mathrm{~b}$. These figures show IRFs generated from the baseline model

\footnotetext{
${ }^{11}$ The dynamics of the model are barely affected by the value of $\eta$ when the financial accelerator is 'switched on'.

${ }^{12}$ The assumption that $\pi^{\Theta}=\widehat{\pi}=0$ may be unduly restrictive in an advanced economy context given the issue of the zero lower bound (ZLB) on nominal interest rates; however, we believe it to be a reasonable simplification in the case of Kenya, where 3-month treasury bill rates and CPI inflation have averaged about $8 \%$ and 9\% respectively over the period 2009-13 (Drummond et al., 2015), so the ZLB is of limited concern.
} 
with and without an operating financial accelerator (FA); 'no FA' means that the (strictly positive) external finance premium (EFP) is fixed to its steady-state value, rather than allowed to increase with farm leverage, to enable comparisons between the two cases.

The negative weather shock leads output $\left(Y_{t}\right)$ to fall below its steady-state value, and inflation $\left(\pi_{t}\right)$ to rise above its steady-state value, which reproduces the stylised facts about supply-side shocks discussed earlier. The rise in the CPI $\left(P_{t}\right)$, and thus in inflation above its steady-state value of 0 , is driven both by an increase in wholesale prices (for goods destined to the wholesale market) and by a depreciation of the nominal exchange rate $\left(S_{t}\right)$ which leads to a rise in the price of imported goods. The effect is qualitatively similar whether or not the FA operates, but the impact of the shock is clearly amplified with the FA in action. With the active FA, two factors decrease the amount of fertiliser $\left(M_{t}\right)$ used by farmers and worsen the effects of the initial shock relative to the no-FA case: (1) the rise in the EFP $\left(s_{t}\right)$ increases borrowing costs for the farms and substantially reduces the amount they borrow $\left(B_{t}\right)$ compared to the case where the external finance premium is fixed; $(2)$ the smaller appreciation of the real exchange rate at which the world fertiliser price is converted to a domestic price means that the cost of fertiliser to farmers falls by less than in the no-FA case.

Given that the IRR places a lower weight on the output gap than on the 'inflation gap' (the deviation of inflation from its steady state), the central bank raises the nominal interest rate in the face of a negative output gap and a positive inflation gap which are of the same size in absolute value. As inflation rises higher with the active FA so too does the nominal interest rate, further depressing output. The eventual recovery in the return on fertiliser $\left(r_{t}^{M}\right)$ helps to replenish farms' net worth $\left(N_{t}\right)$ and eventually brings down their external finance premium in the active FA case. Note that net worth falls by substantially more in the no-FA case because of interest payments on the larger stock of debt which reduce the amount of earnings that are retained and reinvested.

We next consider the economy's response to a persistent positive two-percent shock to the world price of fertiliser $\left(m_{t}^{*}\right)$. IRFs are plotted in Figures $2 \mathrm{a}$ and $2 \mathrm{~b}$ below. Given the small initial change in the real exchange rate, the shock translates into an immediate jump in the domestic fertiliser price. This also leads to a fall in output and a rise in inflation, with the FA clearly amplifying the initial effect of the shock following a process similar to that described in the case of the weather shock. 
Figure 1a: baseline response to a negative weather shock, with and without financial accelerator (FA)
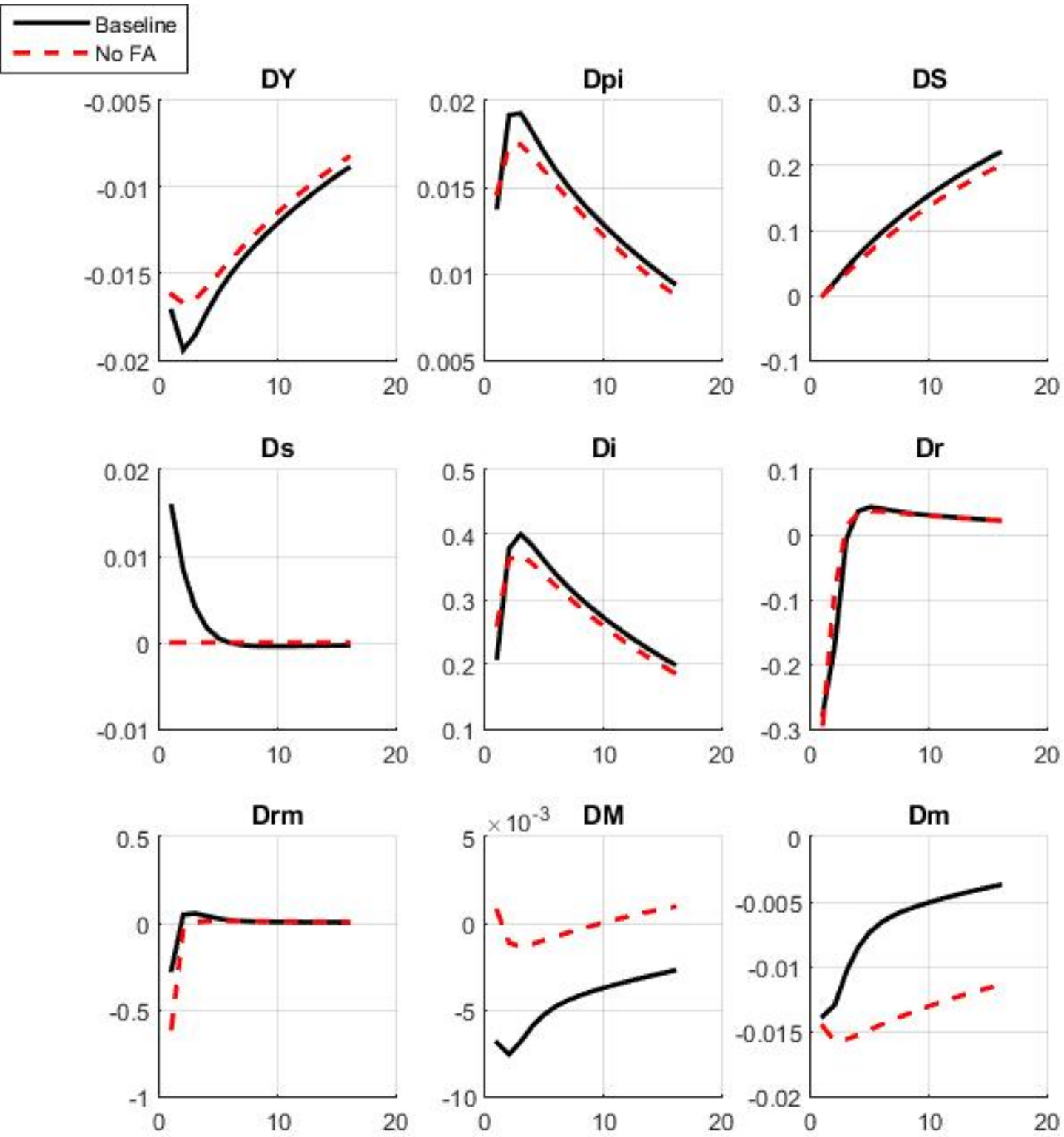

\begin{tabular}{ll}
\hline & \% deviations from steady state \\
DY & GDP \\
Dpi & Inflation (percentage point deviation) \\
DS & Nominal exchange rate \\
Ds & External finance premium \\
Di & Nominal interest rate \\
Dr & Real interest rate \\
Drm & Return on fertiliser \\
DM & Fertiliser used \\
Dm & Real fertiliser price \\
\hline
\end{tabular}


Figure 1b: baseline response to a negative weather shock, with and without financial accelerator (FA) (cont.)
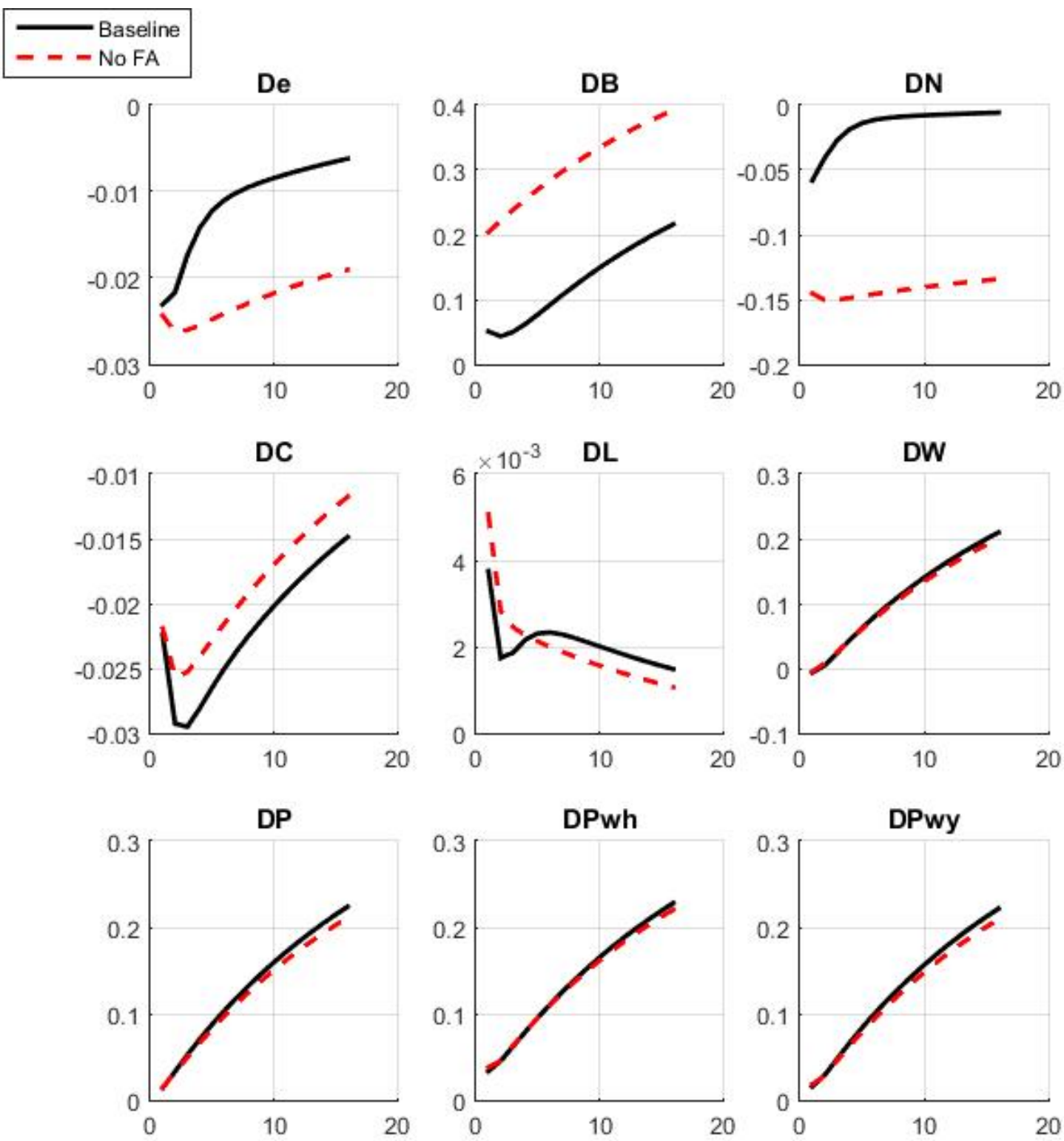

\begin{tabular}{ll}
\hline \multicolumn{2}{c}{ \% deviations from steady state } \\
De & Real exchange rate \\
DB & Bonds \\
DN & Farm net worth \\
DC & Consumption \\
DL & Labour employed \\
DW & Nominal wage \\
DP & CPI \\
DPwh & Domestic wholesale price \\
DPwy & Wholesale price index \\
\hline
\end{tabular}


Figure 2a: baseline response to a positive world fertiliser price shock, with and without financial accelerator (FA)
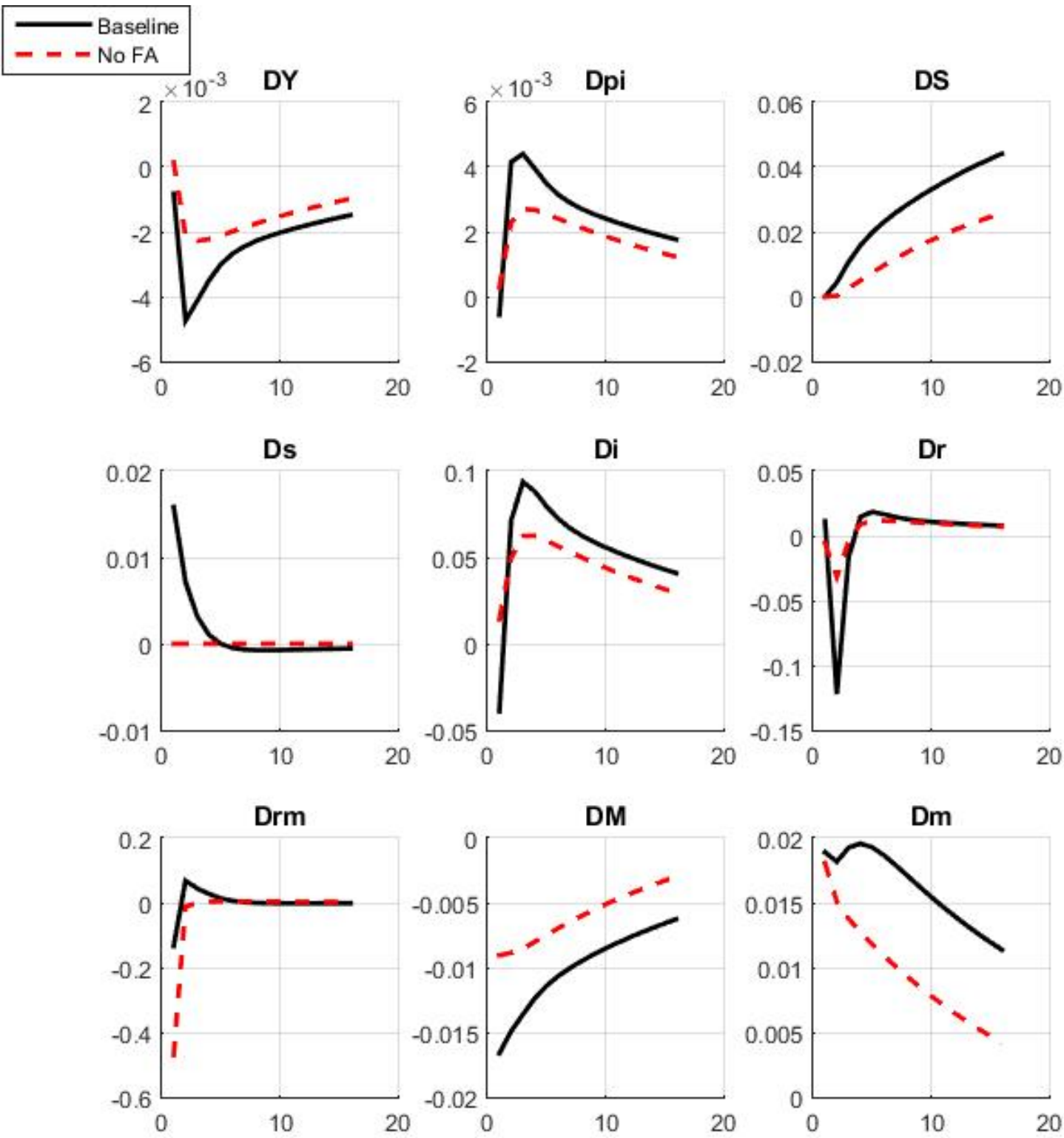

\begin{tabular}{ll}
\hline & \% deviations from steady state \\
DY & GDP \\
Dpi & Inflation (percentage point deviation) \\
DS & Nominal exchange rate \\
Ds & External finance premium \\
Di & Nominal interest rate \\
Dr & Real interest rate \\
Drm & Return on fertiliser \\
DM & Fertiliser used \\
Dm & Real fertiliser price \\
\hline
\end{tabular}


Figure 2b: baseline response to a positive world fertiliser price shock, with and without financial accelerator (FA) (cont.)
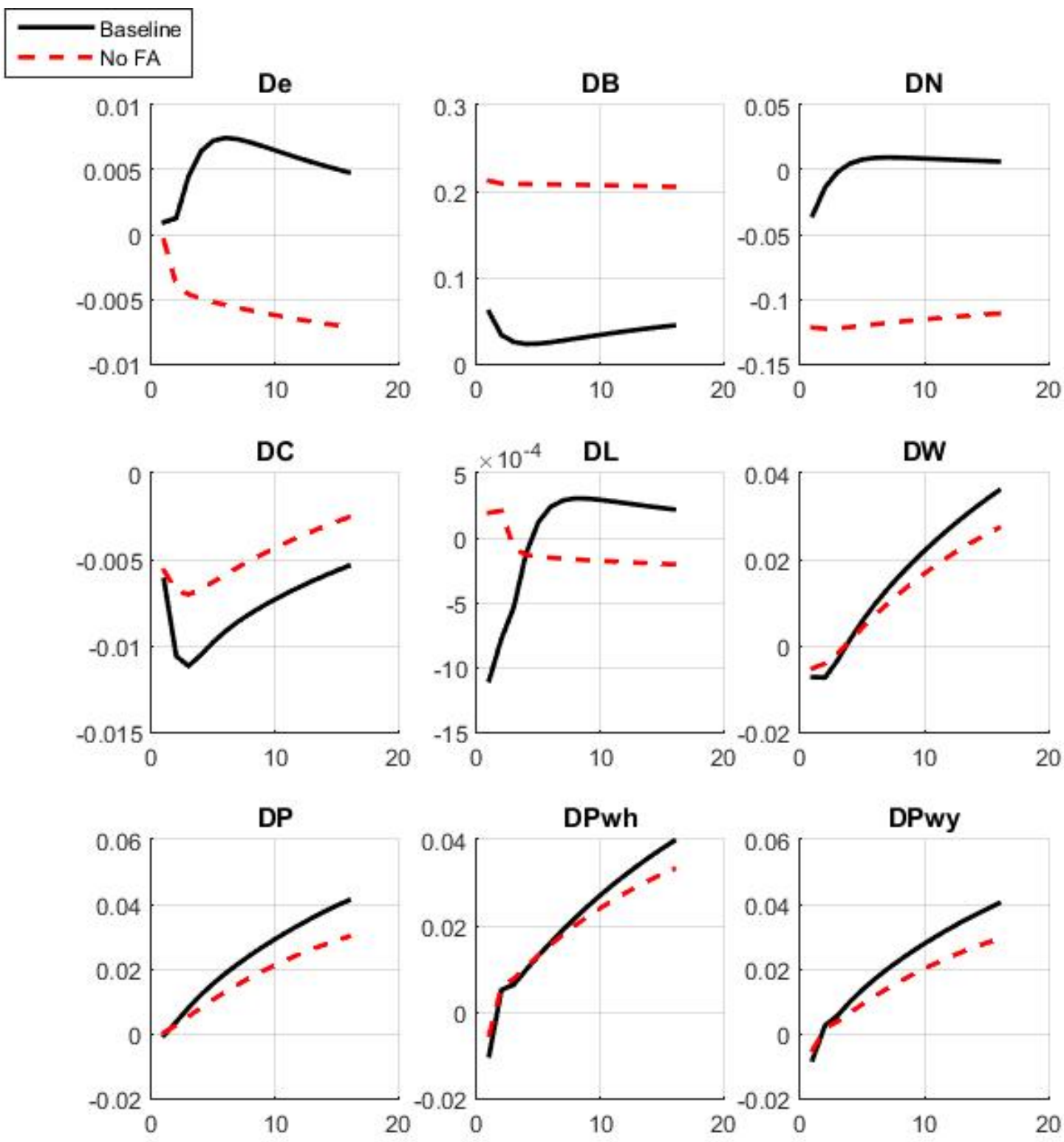

\begin{tabular}{ll}
\hline \multicolumn{2}{c}{ \% deviations from steady state } \\
De & Real exchange rate \\
DB & Bonds \\
DN & Farm net worth \\
DC & Consumption \\
DL & Labour employed \\
DW & Nominal wage \\
DP & CPI \\
DPwh & Domestic wholesale price \\
DPwy & Wholesale price index \\
\hline
\end{tabular}




\section{$5.2 \quad$ Alternative policy rules}

We experimented with a number of alternative IRRs and the fixed exchange rate rule, and tried varying the weights on the arguments of the IRRs to verify the robustness of their effects. We report the main findings of these experiments below, and present IRFs for what appears to be the most desirable IRR (amongst those considered) when the economy is subject to an adverse weather shock and to an adverse world fertiliser price shock. We will consider an IRR to be more desirable than another if it yields (a) lower volatilities of both output and inflation, or (b) a large enough reduction in the volatility of one of the variables to outweigh any rise in the volatility of the other variable for reasonable policymaker preferences over the relative volatilities of the variables. ${ }^{13}$ These criteria were almost always sufficient to rank the IRRs considered, but where they were not ties were broken in favour of IRRs which do not require knowledge of the steady-state real interest rate or the steady-state level of output.

Across all of the different IRRs we experimented with, the one that performed best was a simple IRR of the form

$$
\frac{1+i_{t}}{1+\widehat{r}}=\left(\frac{1+i_{t-1}}{1+\widehat{r}}\right)^{\gamma_{i}}\left(\frac{1+\pi_{t}}{1+\pi^{\Theta}}\right)^{\gamma_{\pi}}
$$

which is collapsed to

$$
1+i_{t}=\left(1+i_{t-1}\right)\left(\frac{1+\pi_{t}}{1+\pi^{\Theta}}\right)^{\gamma_{\pi}}
$$

by setting $\gamma_{i}=1$. This IRR brings a number of practical advantages, especially under model uncertainty which is likely to be a particular concern in an LIC. It does not require an estimate of the steady-state real interest rate, since the $1+\widehat{r}$ denominators on either side of the IRR equation cancel out with $\gamma_{i}=1$. The absence of an output gap term is also advantageous, since estimating the output gap empirically can be a challenge. Current inflation may be hard to estimate in Kenya, but expected inflation is likely to be even harder to estimate given the greater incompleteness of financial markets (and notably the absence of inflation-indexed bonds). Our findings are consistent with, for example, those in the seminal paper of Schmitt-Grohé and Uribe (2007) who find that IRRs which feature a positive response to output can lead to significant welfare losses.

Figures $3 \mathrm{a}$ and $3 \mathrm{~b}$ compare the impulse responses for our baseline and our 'optimal' monetary policy rules in the case of a negative weather shock, and figures $4 \mathrm{a}$ and $4 \mathrm{~b}$ do the same in the case of a positive world fertiliser price shock. Note that we are using the term 'optimal' in the loose sense of 'most desirable amongst the IRRs considered', since we are not, strictly speaking, conducting optimal policy analysis. Under the weather shock, relative to the baseline, the optimal IRR brings about a materially smaller drop in output at its trough, although it slows the recovery of output down somewhat; however, the volatility of inflation is reduced to almost nothing. Under the shock to the world fertiliser price, the optimal IRR brings about a slightly smaller output drop at its trough, while also slowing its recovery down somewhat; inflation volatility is dramatically reduced, however.

\footnotetext{
${ }^{13}$ In other words, assuming that policymakers do not place an unduly large value on either output stabilisation or inflation stabilisation.
} 
Figure 3a: baseline and optimal response to a negative weather shock

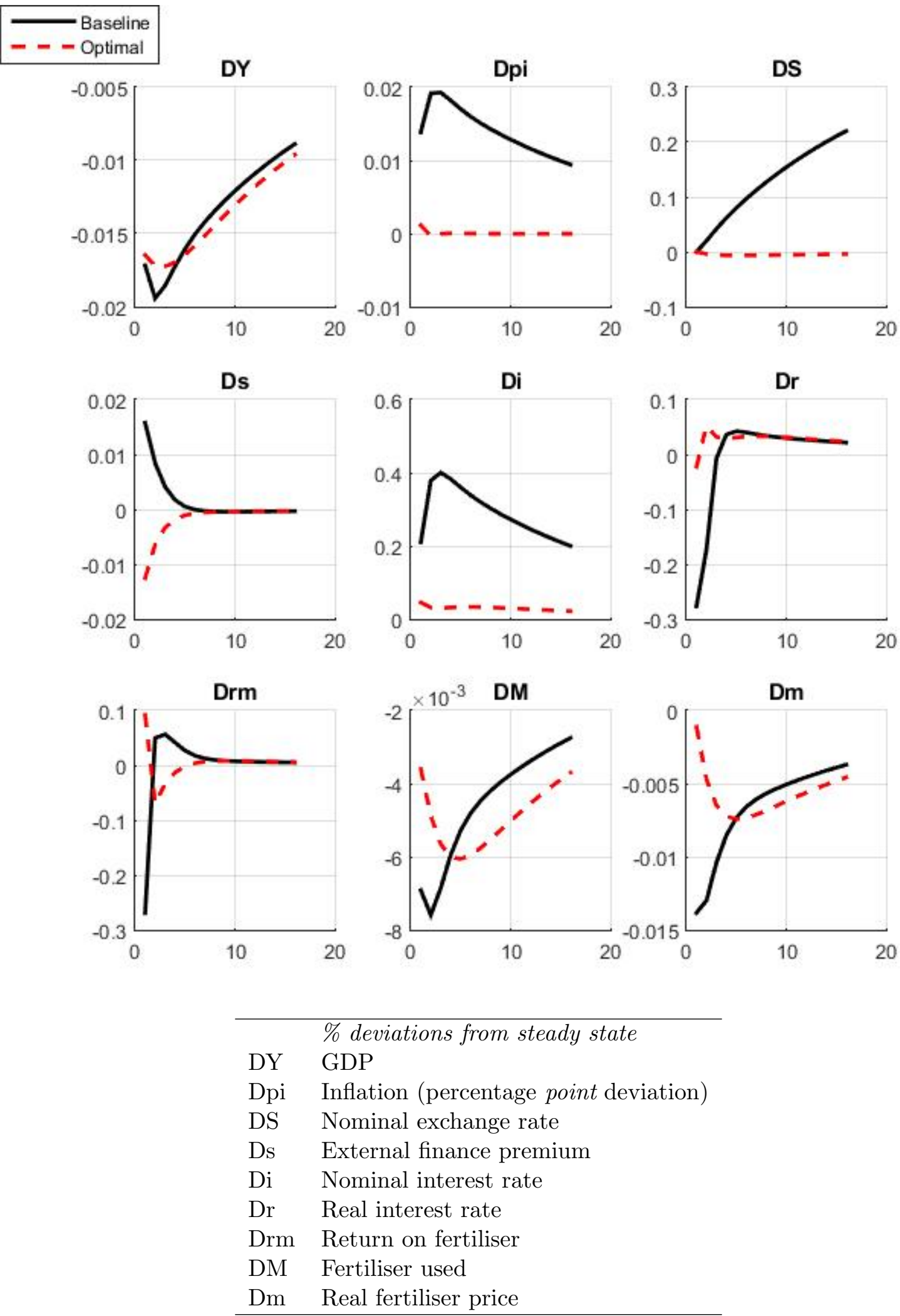


Figure 3b: baseline and optimal response to a negative weather shock (cont.)
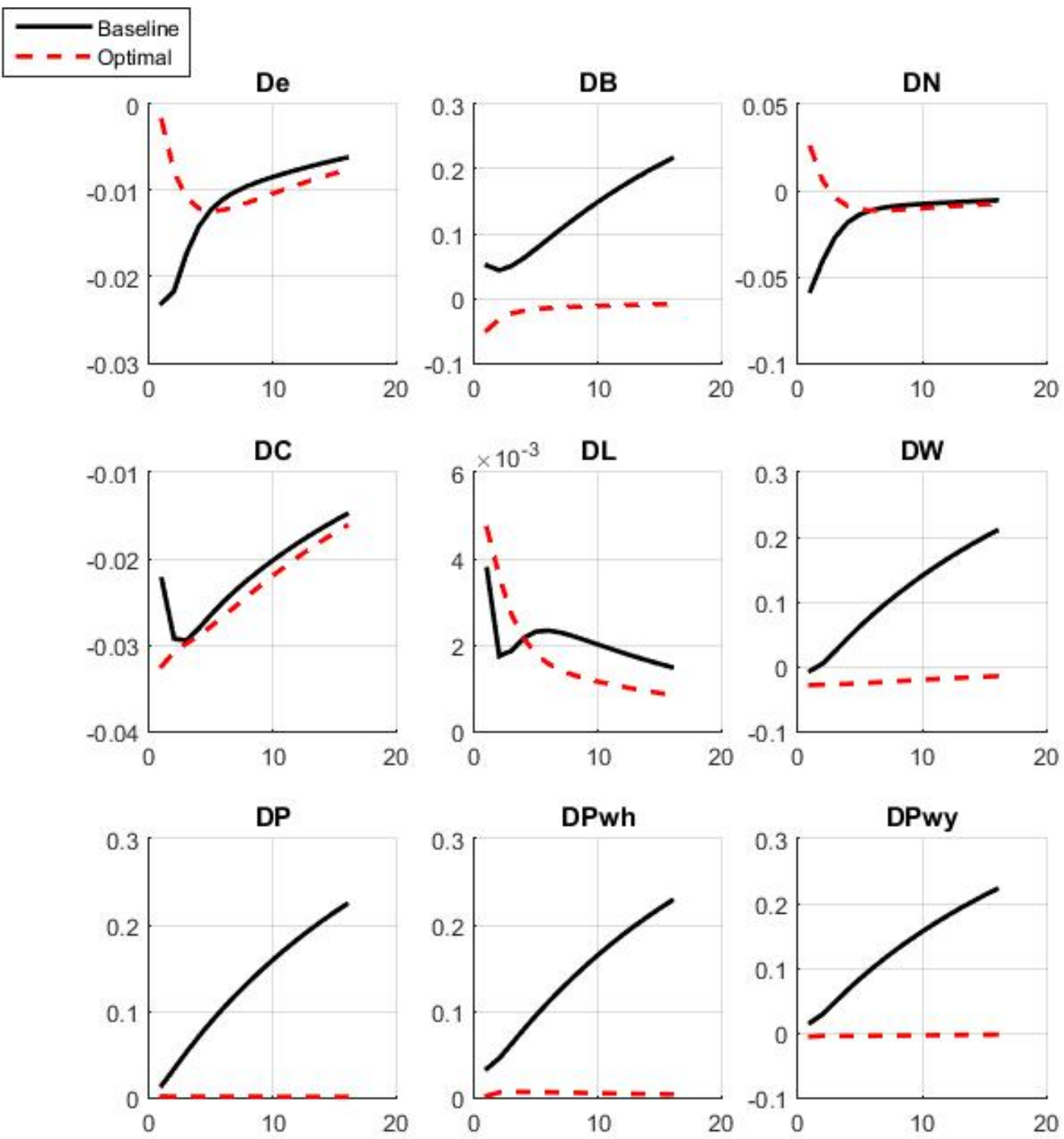

\begin{tabular}{ll}
\hline \multicolumn{2}{c}{ \% deviations from steady state } \\
De & Real exchange rate \\
DB & Bonds \\
DN & Farm net worth \\
DC & Consumption \\
DL & Labour employed \\
DW & Nominal wage \\
DP & CPI \\
DPwh & Domestic wholesale price \\
DPwy & Wholesale price index \\
\hline
\end{tabular}


Figure 4a: baseline and optimal response to a positive world fertiliser price shock
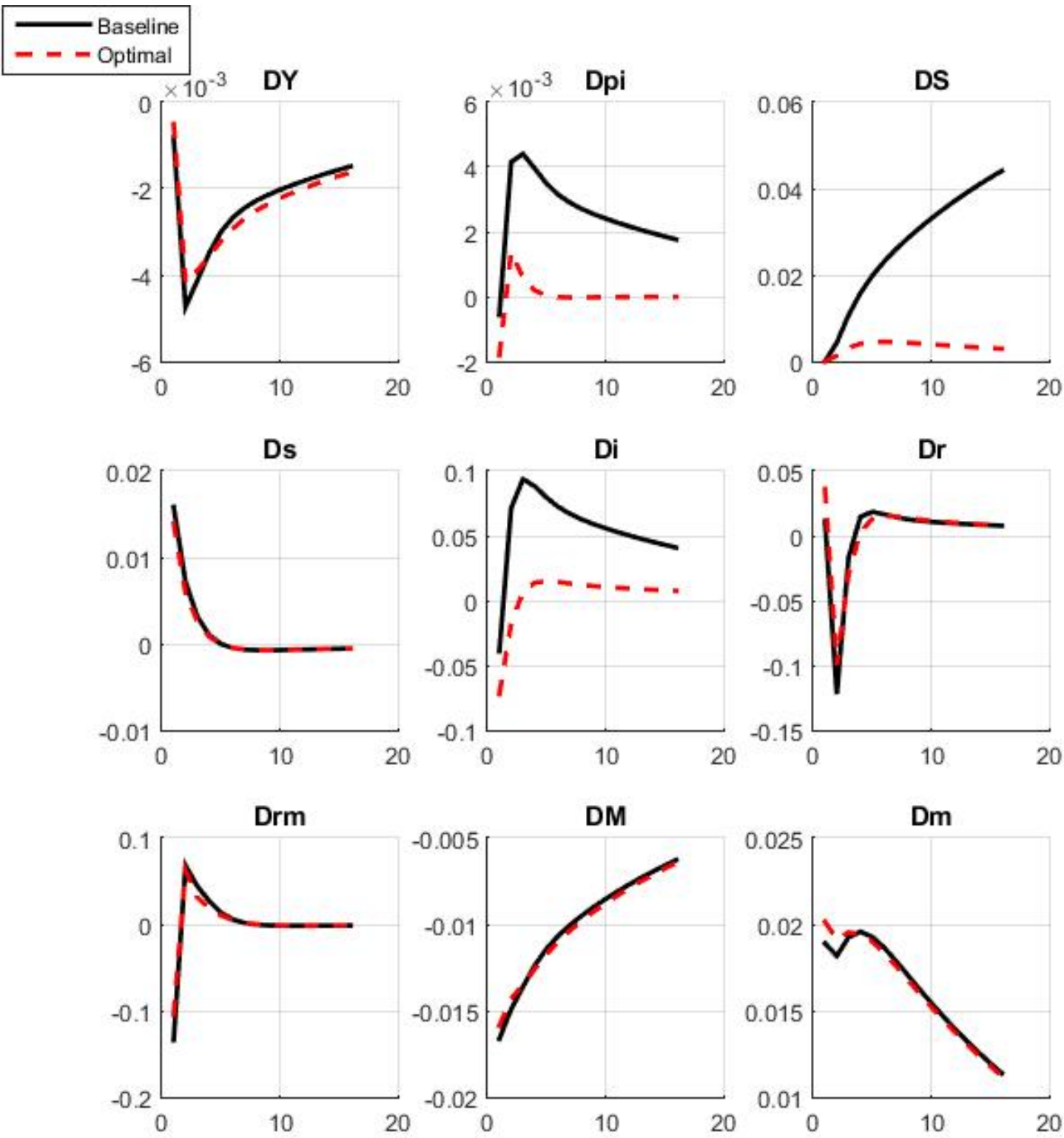

\begin{tabular}{ll}
\hline & \% deviations from steady state \\
DY & GDP \\
Dpi & Inflation (percentage point deviation) \\
DS & Nominal exchange rate \\
Ds & External finance premium \\
Di & Nominal interest rate \\
Dr & Real interest rate \\
Drm & Return on fertiliser \\
DM & Fertiliser used \\
Dm & Real fertiliser price \\
\hline
\end{tabular}


Figure 4b: baseline and optimal response to a positive world fertiliser price shock (cont.)
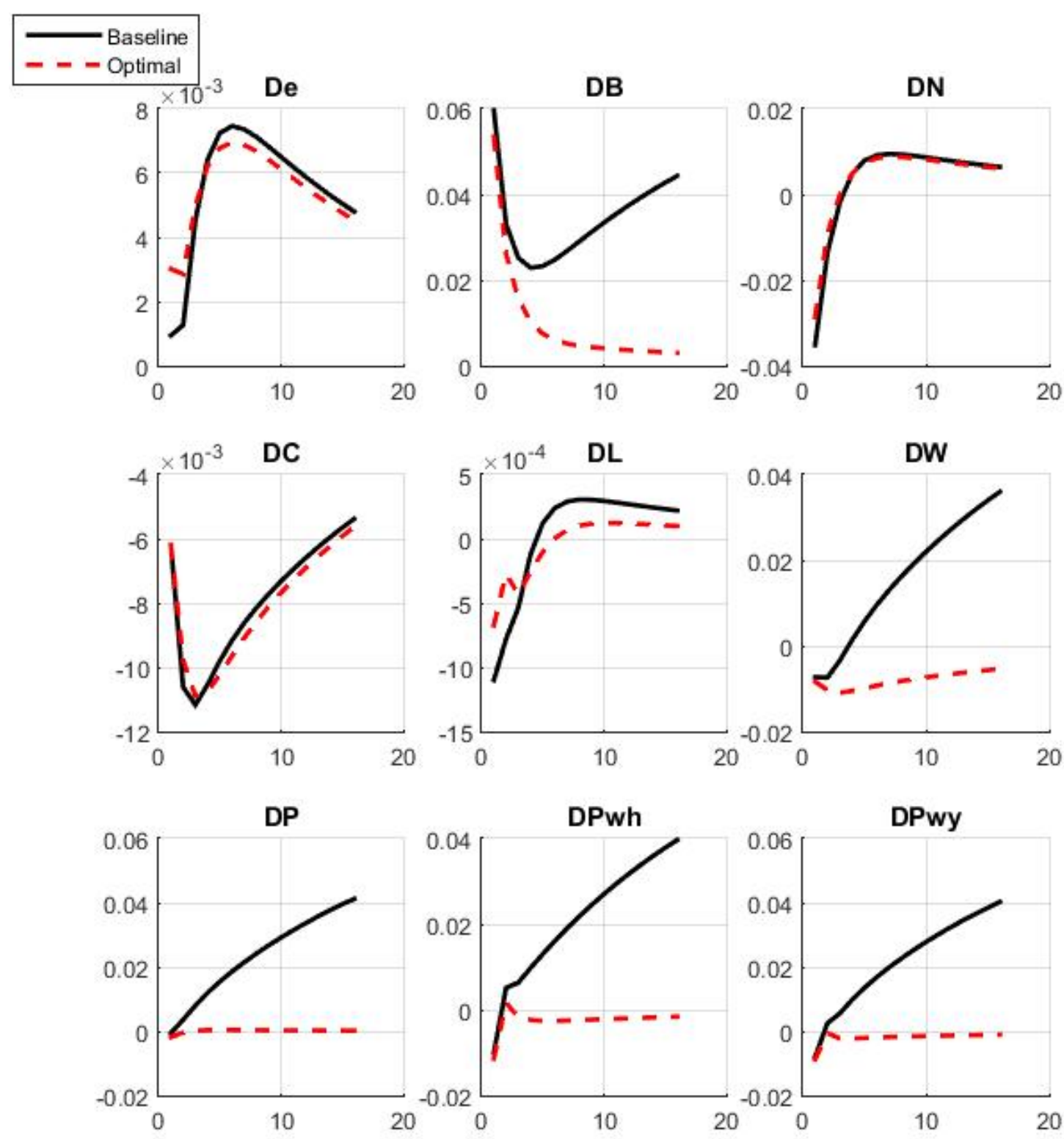

\begin{tabular}{ll}
\hline \multicolumn{2}{c}{ \% deviations from steady state } \\
De & Real exchange rate \\
DB & Bonds \\
DN & Farm net worth \\
DC & Consumption \\
DL & Labour employed \\
DW & Nominal wage \\
DP & CPI \\
DPwh & Domestic wholesale price \\
DPwy & Wholesale price index \\
\hline
\end{tabular}


It remains to be established what role, if any, the financial accelerator plays in our policy analysis. To address this, we plot the impulse response functions for the optimal IRR with and without the financial accelerator in figures $5 \mathrm{a}$ and $5 \mathrm{~b}$ for the weather shock and in figures $6 \mathrm{a}$ and $6 \mathrm{~b}$ for the world fertiliser price shock. Surprisingly, in the case of the weather shock, output falls by less when the financial accelerator operates; inflation is more volatile in this case, although the volatility is low in absolute magnitude. Output falls by more with the financial accelerator because, under the optimal IRR, the EFP falls below its steady-state value rather than rises above it (as was the case under the baseline IRR). The EFP fall allows borrowing to decrease by less which, together with the sharper plunge in the cost of fertiliser induced by a greater exchange rate appreciation, allows for a smaller fall in the quantity of fertiliser used. In the case of the world fertiliser price shock, however, the economy remains more volatile when the financial accelerator operates, as the EFP initially rises above its steady-state value.

We chose to focus our policy analysis on the model with the operating financial accelerator, as we hold this to be the more plausible set-up. We cannot say whether an alternative optimal IRR would have been arrived at with the financial accelerator switched off without more systematic analysis. However, the result that the financial accelerator amplifies the output fall under the baseline IRR but mitigates it under the optimal IRR, at a minimum, points to possible dangers in abstracting from financial frictions when assessing the merits of different policy rules, and especially so in an LIC such as Kenya where financial frictions loom so large. 
Figure 5a: optimal response to a negative weather shock, with and without financial accelerator
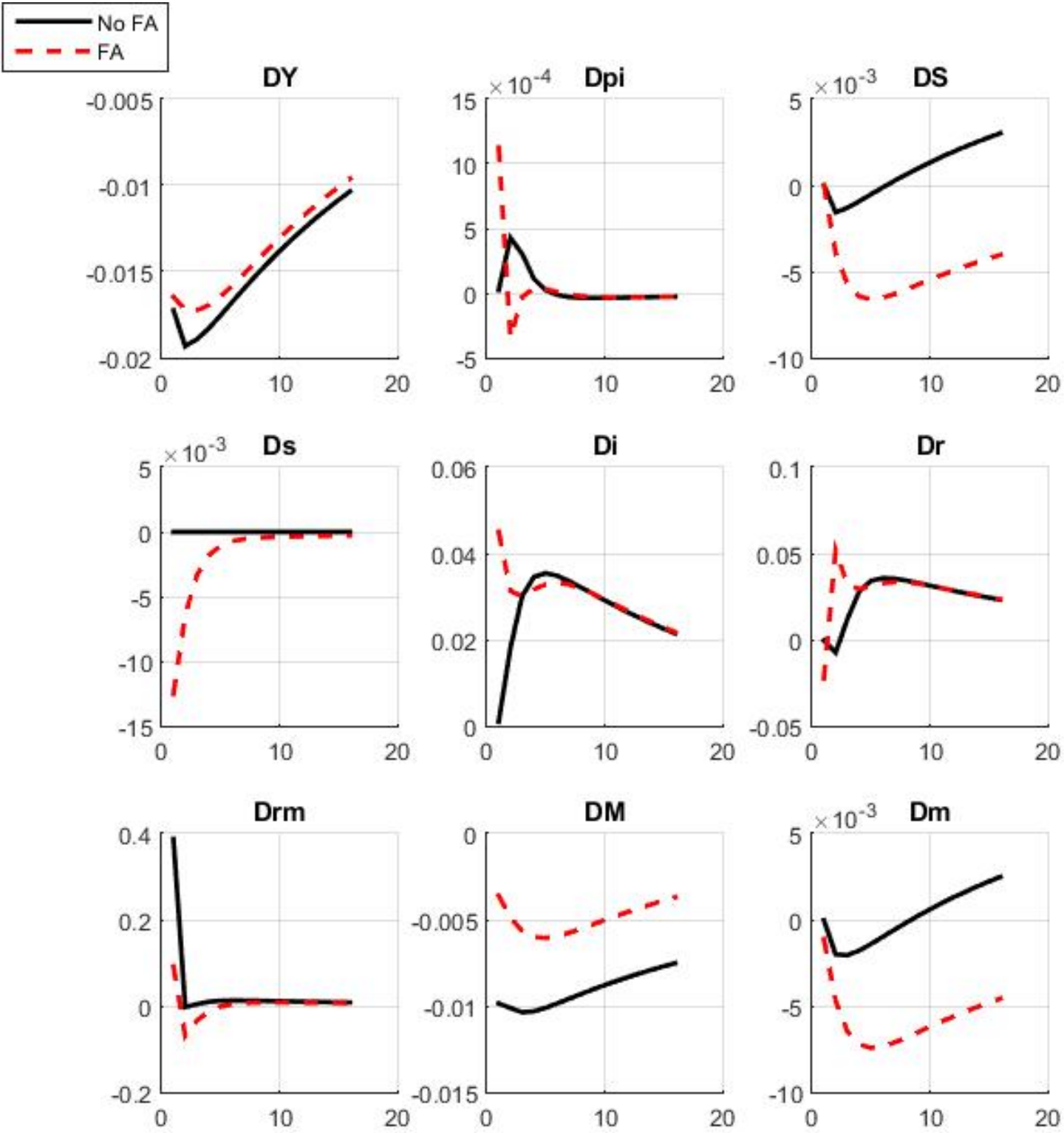

\begin{tabular}{ll}
\hline & \% deviations from steady state \\
DY & GDP \\
Dpi & Inflation (percentage point deviation) \\
DS & Nominal exchange rate \\
Ds & External finance premium \\
Di & Nominal interest rate \\
Dr & Real interest rate \\
Drm & Return on fertiliser \\
DM & Fertiliser used \\
Dm & Real fertiliser price \\
\hline
\end{tabular}


Figure 5b: optimal response to a negative weather shock, with and without financial accelerator (cont.)
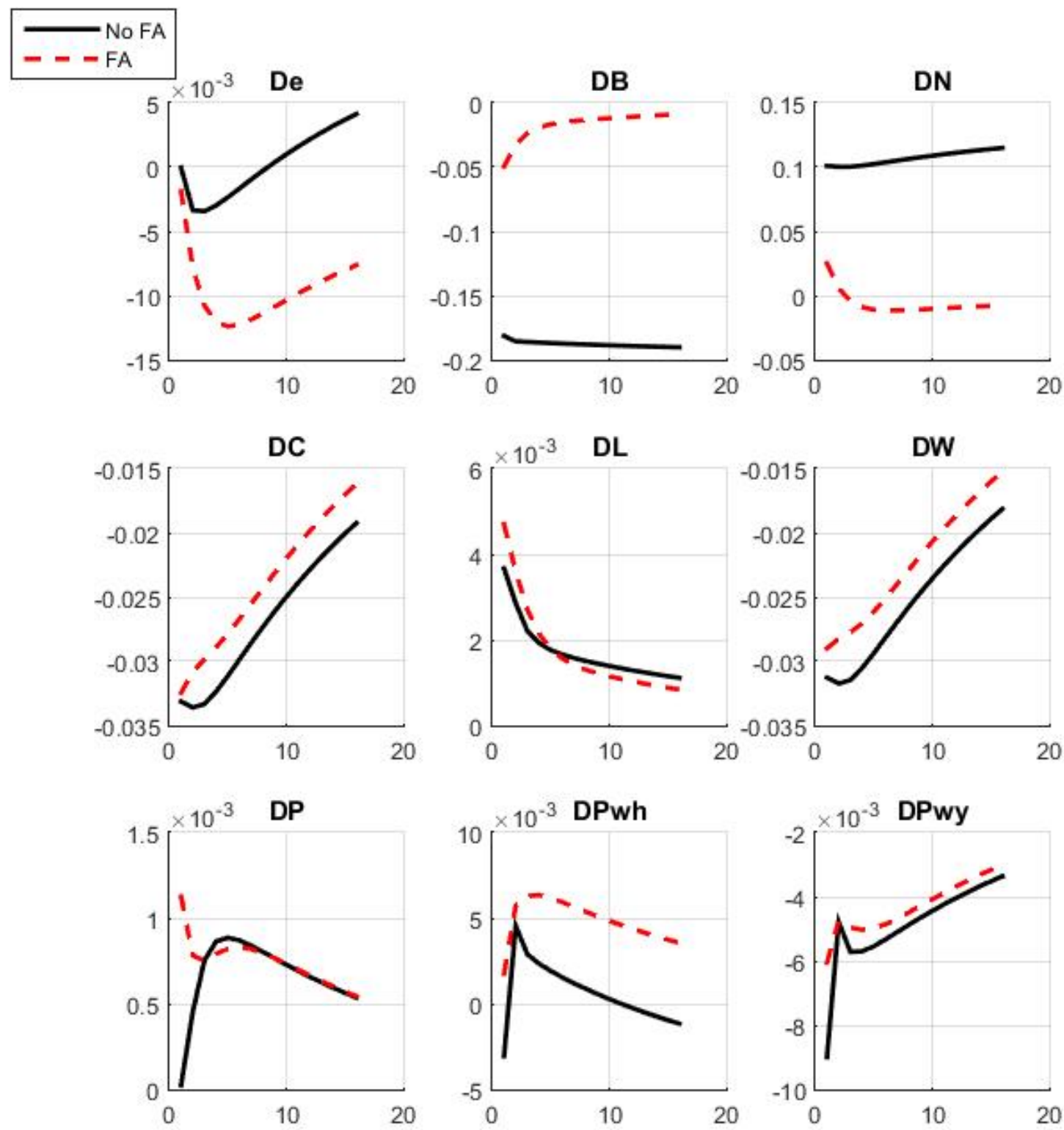

\begin{tabular}{ll}
\hline \multicolumn{2}{c}{ \% deviations from steady state } \\
De & Real exchange rate \\
DB & Bonds \\
DN & Farm net worth \\
DC & Consumption \\
DL & Labour employed \\
DW & Nominal wage \\
DP & CPI \\
DPwh & Domestic wholesale price \\
DPwy & Wholesale price index \\
\hline
\end{tabular}


Figure 6a: optimal response to a positive world fertiliser price shock, with and without financial accelerator
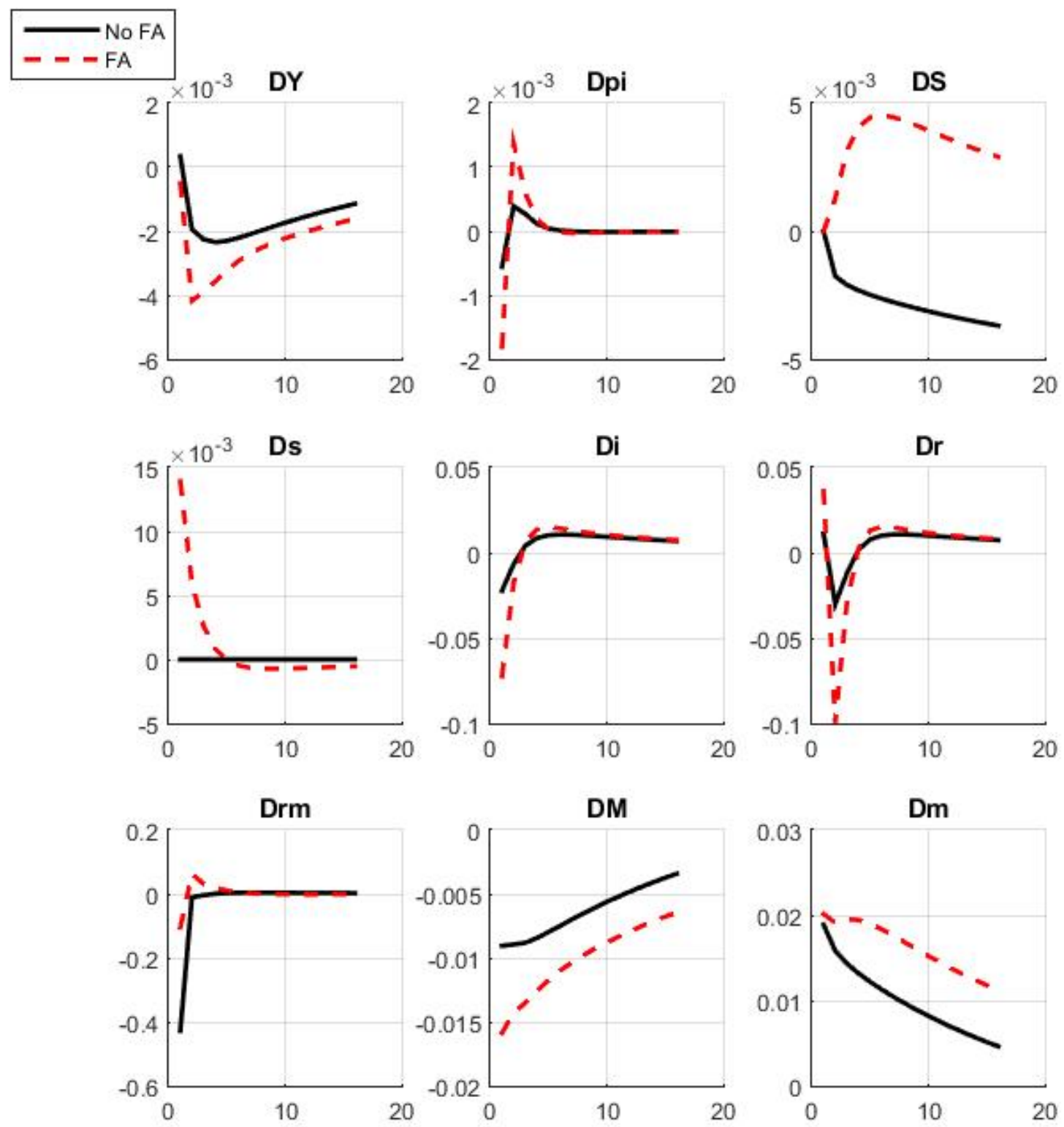

\begin{tabular}{ll}
\hline & \% deviations from steady state \\
DY & GDP \\
Dpi & Inflation (percentage point deviation) \\
DS & Nominal exchange rate \\
Ds & External finance premium \\
Di & Nominal interest rate \\
Dr & Real interest rate \\
Drm & Return on fertiliser \\
DM & Fertiliser used \\
Dm & Real fertiliser price \\
\hline
\end{tabular}


Figure 6b: optimal response to a positive world fertiliser price shock, with and without financial accelerator (cont.)
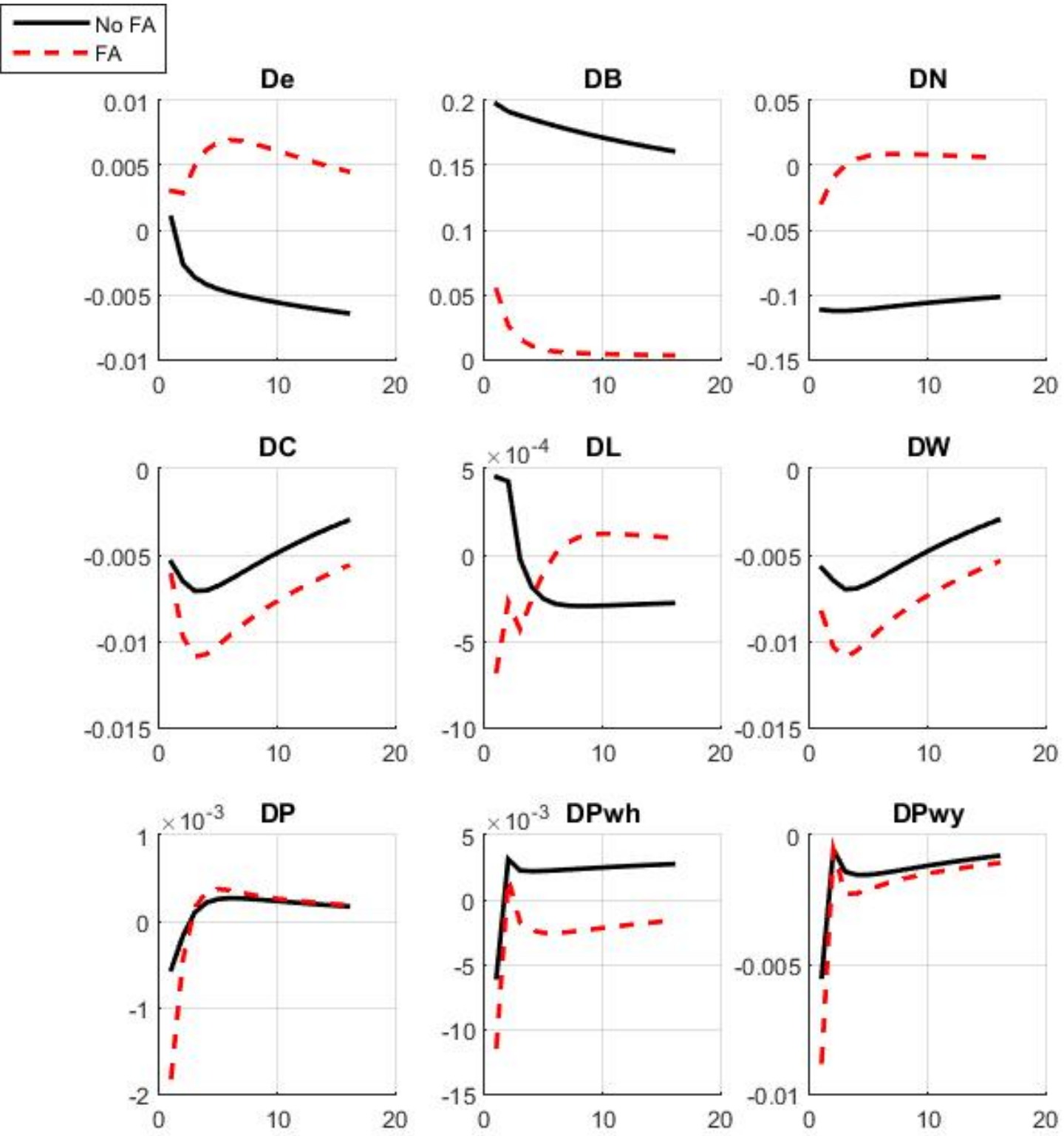

\begin{tabular}{ll}
\hline \multicolumn{2}{c}{ \% deviations from steady state } \\
De & Real exchange rate \\
DB & Bonds \\
DN & Farm net worth \\
DC & Consumption \\
DL & Labour employed \\
DW & Nominal wage \\
DP & CPI \\
DPwh & Domestic wholesale price \\
DPwy & Wholesale price index \\
\hline
\end{tabular}




\subsection{Endogenous fertiliser subsidy}

As a final experiment, we introduce an endogenous subsidy rate to complement the optimal IRR in the presence of a positive shock to the world price of fertiliser. Figures $7 \mathrm{a}$ and $7 \mathrm{~b}$ show the impulse responses in the case of a positive shock to the world fertiliser price for the optimal IRR with and without the endogenous fertiliser subsidy. The stabilising subsidy somewhat reduces the volatility of inflation, but substantially reduces the volatility of output; however, the assumption that government expenditure is funded exclusively by aid and (in effect) lump-sum taxes abstracts from any distortionary effects of government revenue-raising to finance such a subsidy. 
Figure 7a: optimal response to a positive world fertiliser price shock, with and without an endogenous fertiliser subsidy
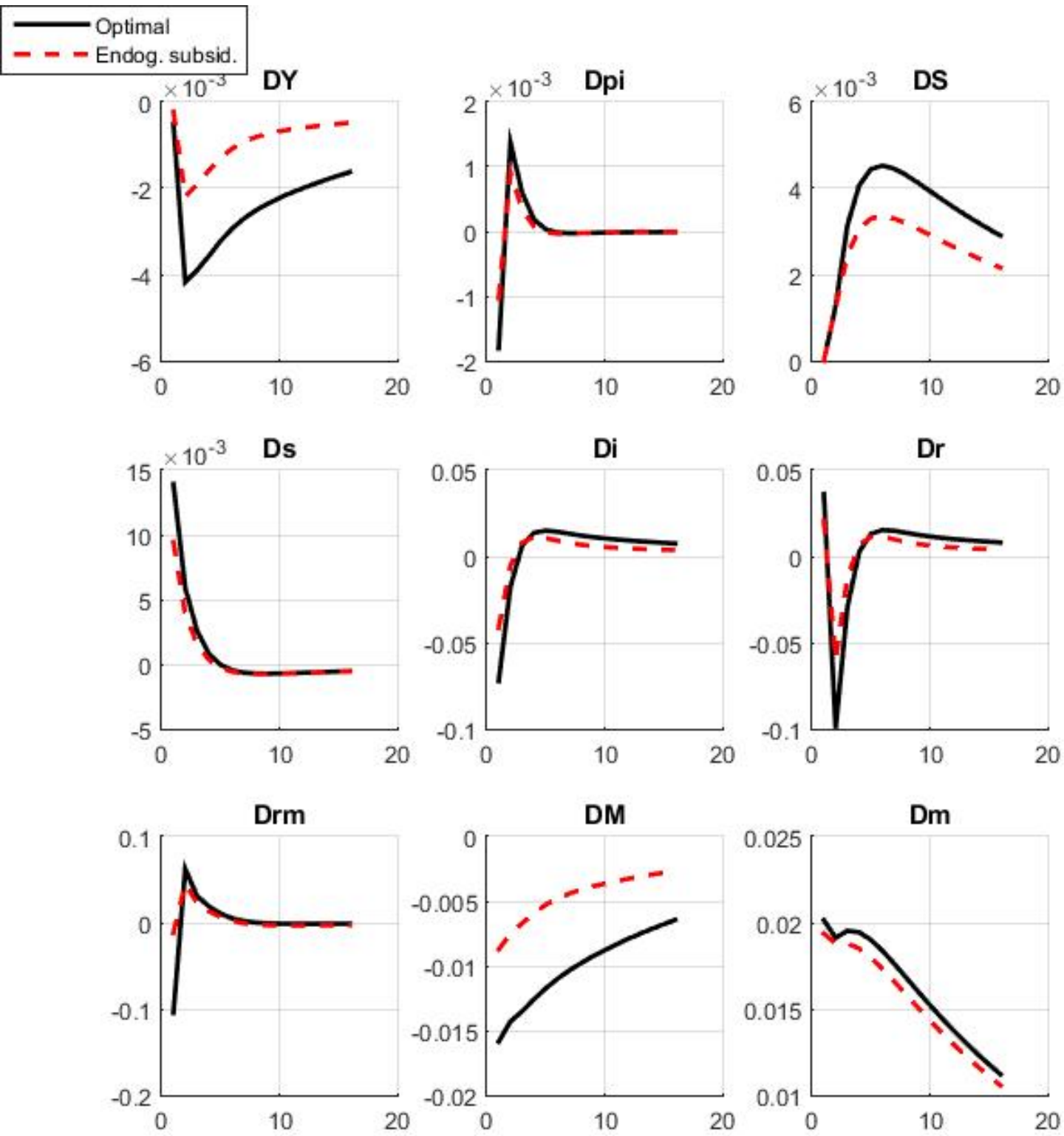

\begin{tabular}{ll}
\hline & \% deviations from steady state \\
DY & GDP \\
Dpi & Inflation (percentage point deviation) \\
DS & Nominal exchange rate \\
Ds & External finance premium \\
Di & Nominal interest rate \\
Dr & Real interest rate \\
Drm & Return on fertiliser \\
DM & Fertiliser used \\
Dm & Real fertiliser price \\
\hline
\end{tabular}


Figure 7b: optimal response to a positive world fertiliser price shock, with and without an endogenous fertiliser subsidy (cont.)
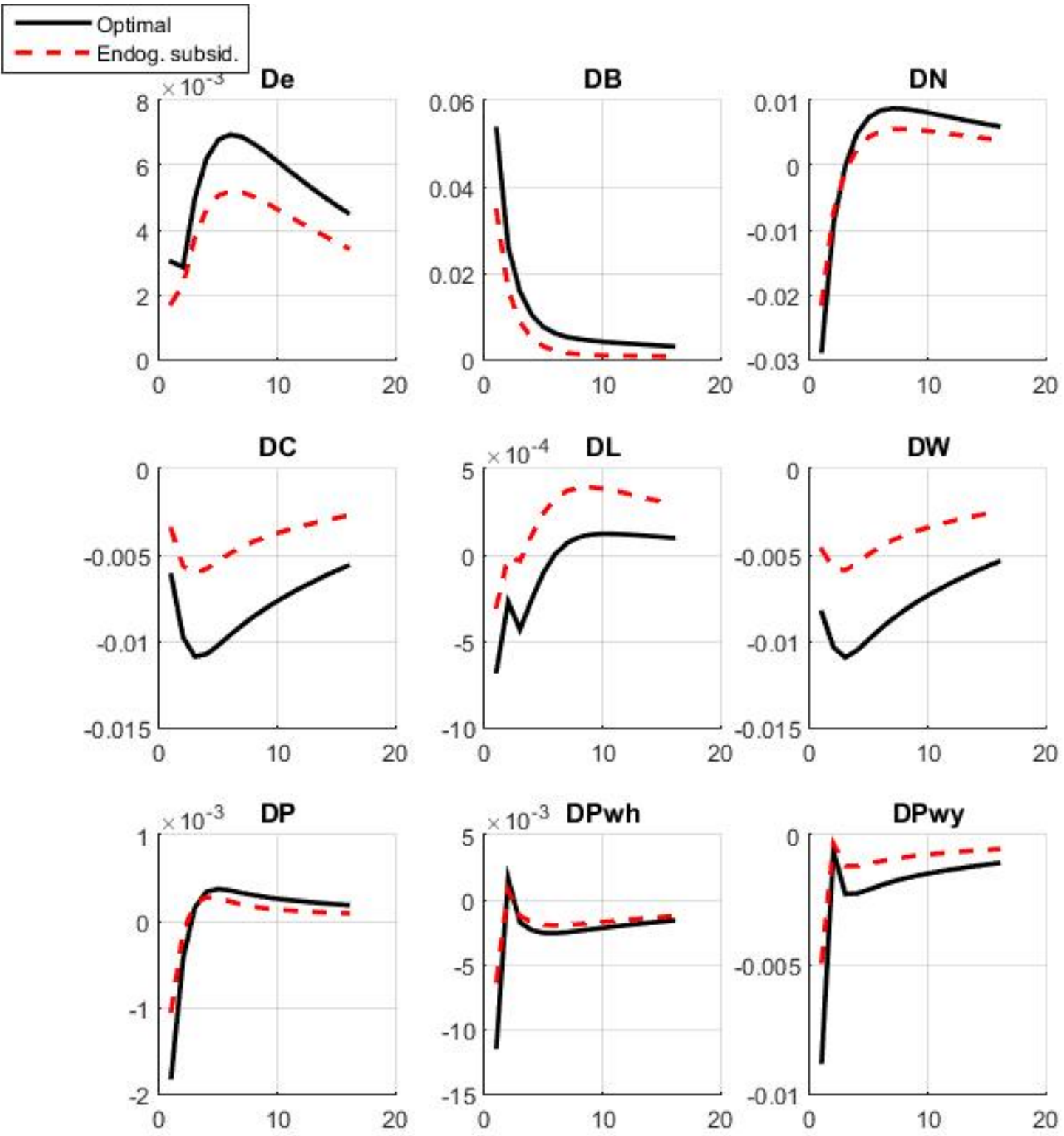

\begin{tabular}{ll}
\hline \multicolumn{2}{c}{ \% deviations from steady state } \\
De & Real exchange rate \\
DB & Bonds \\
DN & Farm net worth \\
DC & Consumption \\
DL & Labour employed \\
DW & Nominal wage \\
DP & CPI \\
DPwh & Domestic wholesale price \\
DPwy & Wholesale price index \\
\hline
\end{tabular}




\section{Conclusions}

This paper has developed a model which seeks to provide an adequate characterisation of the economy of a typical LIC, and does so by adapting the financial accelerator mechanism to LICs whose economies are heavily dependent upon agriculture. We have parameterised the model to be appropriate for Kenya and used it to conduct simulations to pinpoint desirable policy responses to adverse weather shocks and adverse world fertiliser price shocks. In our baseline analysis, where the monetary authority follows a Taylor-type interest rate rule with standard weights, we were able to replicate the stylised fact that adverse supply shocks lead to a rise in inflation and a fall in output. Comparing the outcomes of our baseline model with an operating and a muted financial accelerator shows a material impact from the financial accelerator, which clearly amplifies the effects of both types of shock considered.

We examined the properties of a range of alternative interest rate rules, in the face of supply-side shocks, and found the most desirable one to be a simple rule according to which the policy interest rate is set based only on its lag and on the deviation of contemporaneous inflation from its target. This would be the most desirable interest rate rule from the point of view of a central bank (with reasonable preferences) which wishes to minimise the deviations of output and inflation from their targets, and which may be faced with uncertainly about the underlying structure of the economy it oversees.

To assess the role of the financial accelerator in our policy analysis, we compared the outcomes of the model under the most desirable interest rate rule with an operating and a muted financial accelerator. We found that in the case of the weather shock alone, output falls by noticeably less when the financial accelerator operates (while inflation is somewhat more volatile). This points to possible dangers in abstracting from financial frictions when assessing the merits of different policy rules, and particularly so in an LIC such as Kenya where financial frictions loom especially large.

In a final experiment, we introduced a countercyclical fertiliser subsidy, to complement the most desirable interest rate rule which we arrived at, in a bid to offset an adverse shock to the world price of fertiliser. The stabilising subsidy somewhat decreases the volatility of inflation and substantially reduces the volatility of output. Nonetheless, the assumption that government expenditure is funded exclusively by aid and (in effect) lump-sum taxes abstracts from any distortionary effects of government revenue-raising to finance such a subsidy. This, together with possible risks to fiscal sustainability from the narrow tax bases typical of LICs, are cause for great caution in considering such a subsidy as a serious policy proposal.

Our model is amenable to a number of extensions, so as more comprehensively to adapt it to an LIC setting. One could bring financial frictions to bear on households as well as on producers and/or consider the role of subsistence consumption. One could also introduce a non-agricultural sector, to be able to contrast the behaviour of core and headline inflation and study the desirability of targeting one or the other. One could restrict the government to financing its expenditure through distortionary taxation and non-concessionary debt, so as better to evaluate the merits of countercyclical fertiliser subsidies. Finally, one could consider shocks to the economy other than supply-side shocks to assess the robustness of the interest rate rules found to be preferable in this study. 


\section{Appendix 1 Derivation of the financial acceler- ator equations}

The derivation of the equations for the financial accelerator mechanism is given in Bernanke et al. (1999) and Gertler et al. (2003). Using their results, this appendix outlines the derivation of the financial accelerator equations which appear in our model.

The idiosyncratic shock to farm productivity $\omega_{t}$ is distributed according to $\ln \omega \sim$ $N\left(-\frac{1}{2} \sigma_{\omega}^{2}, \sigma_{\omega}^{2}\right)$, where the time subscript on $\omega_{t}$ is omitted since the shock is an i.i.d. random variable. To simplify subsequent equations, we introduce a variable $z_{t}$ defined by

$$
z_{t} \equiv \frac{\ln \left(\bar{\omega}_{t}\right)+\frac{1}{2} \sigma_{\omega}^{2}}{\sigma_{\omega}}
$$

where $\bar{\omega}_{t}$ is the bankruptcy threshold of the idiosyncratic shock to farm productivity.

The Lagrange multiplier on lenders' constraint that the expected return on lending equals its opportunity cost is:

$$
\Lambda\left(\bar{\omega}_{t}\right)=\frac{\Gamma^{\prime}\left(\bar{\omega}_{t}\right)}{\Gamma^{\prime}\left(\bar{\omega}_{t}\right)-\tau G^{\prime}\left(\bar{\omega}_{t}\right)}=\left[1-\tau \frac{G^{\prime}\left(\bar{\omega}_{t}\right)}{\Gamma^{\prime}\left(\bar{\omega}_{t}\right)}\right]^{-1},
$$

where

$$
G\left(\bar{\omega}_{t}\right)=\int_{0}^{\bar{\omega}_{t}} \omega f(\omega) \mathrm{d} \omega
$$

so that $\tau G\left(\bar{\omega}_{t}\right)$ are expected monitoring costs, thus

$$
G^{\prime}\left(\bar{\omega}_{t}\right)=\frac{\mathrm{d}}{\mathrm{d} \bar{\omega}_{t}} \int_{0}^{\bar{\omega}_{t}} \omega f(\omega) \mathrm{d} \omega=\bar{\omega}_{t} f\left(\bar{\omega}_{t}\right)
$$

and the expected gross share of profits to lender is

$$
\Gamma\left(\bar{\omega}_{t}\right)=\int_{0}^{\bar{\omega}_{t}} \omega f(\omega) \mathrm{d} \omega+\bar{\omega}_{t} \int_{\bar{\omega}_{t}}^{\infty} f(\omega) \mathrm{d} \omega=\Phi\left(z_{t}-\sigma_{\omega}\right)+\bar{\omega}_{t}\left[1-\Phi\left(z_{t}\right)\right],
$$

since $\ln \omega \sim N\left(-\frac{1}{2} \sigma_{\omega}^{2}, \sigma_{\omega}^{2}\right)$, where $\Phi(\cdot)$ is the standard normal cumulative distribution function; it follows that

$$
\Gamma^{\prime}\left(\bar{\omega}_{t}\right)=1-\Phi\left(z_{t}\right)
$$

Therefore,

$$
\Lambda\left(\bar{\omega}_{t}\right)=\left[1-\tau \frac{\bar{\omega}_{t} f\left(\bar{\omega}_{t}\right)}{1-\Phi\left(z_{t}\right)}\right]^{-1} .
$$

The expected gross share of profits to the lender is

$$
\Gamma\left(\bar{\omega}_{t}\right)=\Phi\left(z_{t}-\sigma_{\omega}\right)+\bar{\omega}_{t}\left[1-\Phi\left(z_{t}\right)\right],
$$

with $0 \leq \Gamma\left(\bar{\omega}_{t}\right) \leq 1$ by construction. The net share of profits to the lender (net of monitoring costs) is:

$$
\Gamma\left(\bar{\omega}_{t}\right)-\tau G\left(\bar{\omega}_{t}\right) .
$$


Since

$$
G\left(\bar{\omega}_{t}\right)=\int_{0}^{\bar{\omega}_{t}} \omega f(\omega) \mathrm{d} \omega
$$

then

$$
G\left(\bar{\omega}_{t}\right)=\Phi\left(z_{t}-\sigma_{\omega}\right)
$$

therefore

$$
\Gamma\left(\bar{\omega}_{t}\right)-\tau G\left(\bar{\omega}_{t}\right)=(1-\tau) \Phi\left(z_{t}-\sigma_{\omega}\right)+\bar{\omega}_{t}\left[1-\Phi\left(z_{t}\right)\right] .
$$

Let $s\left(\bar{\omega}_{t}\right)$ be the external finance premium and $k\left(\bar{\omega}_{t}\right)$ the ratio of the value of subsidised fertiliser purchased to net worth (the leverage), which are both functions of the idiosyncratic shock's bankruptcy threshold. The first-order conditions for the contracting problem imply that

$$
s\left(\bar{\omega}_{t}\right)=\frac{\Lambda\left(\bar{\omega}_{t}\right)}{1-\Gamma\left(\bar{\omega}_{t}\right)+\Lambda\left(\bar{\omega}_{t}\right)\left[\Gamma\left(\bar{\omega}_{t}\right)-\tau G\left(\bar{\omega}_{t}\right)\right]}
$$

and

$$
k\left(\bar{\omega}_{t}\right)=1+\frac{\Lambda\left(\bar{\omega}_{t}\right)\left[\Gamma\left(\bar{\omega}_{t}\right)-\tau G\left(\bar{\omega}_{t}\right)\right]}{1-\Gamma\left(\bar{\omega}_{t}\right)}
$$

with

$$
k_{t}\left(\bar{\omega}_{t}\right) \equiv \frac{\kappa m_{t} M_{t}}{N_{t}}
$$




\section{Appendix 2 Model equations}

Demand side

$$
\begin{aligned}
& Y_{t}=Q_{t}+G+\tau \int_{0}^{\bar{\omega}_{t}} \omega_{t}\left(1+r_{t}^{M}\right) \kappa_{t} m_{t-1} M_{t} \mathrm{~d} \mathcal{F}\left(\omega_{t}\right)+\xi, \\
& \lambda_{t}=(1-\varsigma)\left(C_{t}\right)^{(\nu-1)(\varsigma-1)-1}\left(1-L_{t}\right)^{\varsigma(1-\nu)} \\
& \lambda_{t}=\beta \mathbb{E}_{t}\left[\lambda_{t+1}\left(1+i_{t}\right) \frac{P_{t}}{P_{t+1}}\right] \\
& C_{t}=\left[(\gamma)^{1 / \rho}\left(C_{t}^{H}\right)^{(\rho-1) / \rho}+(1-\gamma)^{1 / \rho}\left(C_{t}^{M}\right)^{(\rho-1) / \rho}\right]^{\rho /(\rho-1)} \\
& \frac{C_{t}^{H}}{C_{t}^{M}}=\frac{\gamma}{1-\gamma}\left(\frac{P_{R, t}^{H}}{P_{R, t}^{M}}\right)^{-\rho} \\
& P_{t}=\left[(\gamma)\left(P_{R, t}^{H}\right)^{1-\rho}+(1-\gamma)\left(P_{R, t}^{M}\right)^{1-\rho}\right]^{1 /(1-\rho)} \\
& \frac{C_{t}^{X}}{C_{t}^{H}}=\left[\left(\frac{\alpha}{1-\alpha}\right)\left(\frac{P_{W, t}^{X}}{P_{W, t}^{H}}\right)\right]^{\sigma} \\
& L_{t}=\left[\frac{\alpha_{L} P_{W, t}^{Y}}{W_{t}}\right]^{\Sigma} A_{t}^{\Sigma-1} Y_{t} \\
& \mathbb{E}_{t}\left[1+r_{t+1}^{M}\right]=\frac{1}{\kappa_{t} m_{t}} \mathbb{E}_{t}\left[\frac{P_{W, t+1}^{Y}}{P_{t+1}} \alpha_{M} A_{t+1}^{(\Sigma-1) / \Sigma}\left(\frac{Y_{t+1}}{M_{t+1}}\right)^{1 / \Sigma}\right]
\end{aligned}
$$

Supply side

$$
\begin{gathered}
Y_{t}=A_{t}\left[\alpha_{M} M_{t}^{\delta}+\alpha_{L} L_{t}^{\delta}\right]^{1 / \delta} \\
(1-\varsigma) \frac{1}{C_{t}} \frac{W_{t}}{P_{t}}=\varsigma \frac{1}{1-L_{t}} \\
\mathbb{E}_{t}\left[1+r_{t+1}^{M}\right]=s\left(\frac{N_{t+1}}{\kappa_{t} m_{t} M_{t+1}}\right) \mathbb{E}_{t}\left[\left(1+i_{t}\right) \frac{P_{t}}{P_{t+1}}\right]
\end{gathered}
$$


Pricing, interest rates, exchange rates

$$
\begin{gathered}
P_{W, t}^{Q}=\frac{P_{W, t}^{H} C_{t}^{H}+P_{W, t}^{X} C_{t}^{X}}{Q_{t}} \\
P_{W, t}^{Y}=\frac{P_{W, t}^{Q} Q_{t}+P_{W, t}^{H} G+P_{W, t}^{Y} \tau \int_{0}^{\bar{\omega}_{t}} \omega_{t}\left(1+r_{t}^{M}\right) \kappa_{t} m_{t-1} M_{t} \mathrm{~d} \mathcal{F}\left(\omega_{t}\right)}{Y_{t}} \\
\frac{P_{R, t}^{H}}{P_{R, t-1}^{H}}=\left(\mu \frac{P_{W, t}^{H}}{P_{R, t}^{H}}\right)^{\lambda_{p}} \mathbb{E}_{t}\left(\frac{P_{R, t+1}^{H}}{P_{R, t}^{H}}\right)^{\beta} \\
P_{R, t}^{M}=\mu^{f} S_{t} \\
e_{t}=\frac{S_{t} P_{R, t}^{M *}}{P_{R, t}^{H}}=\frac{S_{t} \mu^{f}}{P_{R, t}^{H}} \\
P_{W, t}^{X}=S_{t}
\end{gathered}
$$

\section{Budget constraints and other identities}

$$
\begin{gathered}
\frac{B_{t+1}}{P_{t}}=\kappa_{t} m_{t} M_{t+1}-N_{t+1} \\
N_{t+1}=\eta V_{t}+\zeta \\
V_{t}=\left(1+r_{t}^{M}\right) \kappa_{t} m_{t-1} M_{t}-\left(1+i_{t-1}\right) \frac{B_{t}}{P_{t}}-\tau \int_{0}^{\bar{\omega}_{t}} \omega_{t}\left(1+r_{t}^{M}\right)_{t} m_{t-1} M_{t} \mathrm{~d} \mathcal{F}\left(\omega_{t}\right) \\
B_{t}=B_{t}^{H}+B_{t}^{F} \\
1+\pi_{t}=\frac{P_{t}}{P_{t-1}} \\
m_{t}=\frac{S_{t}}{P_{t}} m_{t}^{*} \\
1+r_{t+1}=\left(1+i_{t}\right) \frac{P_{t}}{P_{t+1}} \\
Q_{t}=\psi\left[\alpha\left(C_{t}^{H}\right)^{(\sigma+1) / \sigma}+(1-\alpha)\left(C_{t}^{X}\right)^{(\sigma+1) / \sigma}\right]^{\sigma /(\sigma+1)}
\end{gathered}
$$


Financial accelerator

$$
\begin{gathered}
z_{t}=\frac{\ln \left(\bar{\omega}_{t}\right)+\frac{1}{2} \sigma_{\omega}^{2}}{\sigma_{\omega}} \\
\Lambda\left(\bar{\omega}_{t}\right)=\left[1-\tau \frac{\bar{\omega}_{t} f\left(\bar{\omega}_{t}\right)}{1-\Phi\left(z_{t}\right)}\right]^{-1} \\
\Gamma\left(\bar{\omega}_{t}\right)=\Phi\left(z_{t}-\sigma_{\omega}\right)+\bar{\omega}_{t}\left[1-\Phi\left(z_{t}\right)\right] \\
\Gamma\left(\bar{\omega}_{t}\right)-\tau G\left(\bar{\omega}_{t}\right)=(1-\tau) \Phi\left(z_{t}-\sigma_{\omega}\right)+\bar{\omega}_{t}\left[1-\Phi\left(z_{t}\right)\right] \\
s\left(\bar{\omega}_{t}\right)=\frac{\Lambda\left(\bar{\omega}_{t}\right)}{1-\Gamma\left(\bar{\omega}_{t}\right)+\Lambda\left(\bar{\omega}_{t}\right)\left[\Gamma\left(\bar{\omega}_{t}\right)-\tau G\left(\bar{\omega}_{t}\right)\right]} \\
k_{t}\left(\bar{\omega}_{t}\right)=1+\frac{\Lambda\left(\bar{\omega}_{t}\right)\left[\Gamma\left(\bar{\omega}_{t}\right)-\tau G\left(\bar{\omega}_{t}\right)\right]}{1-\Gamma\left(\bar{\omega}_{t}\right)} \\
k_{t}\left(\bar{\omega}_{t}\right)=\frac{\kappa_{t} m_{t} M_{t}}{N_{t}}
\end{gathered}
$$

Government budget constraint

$$
\frac{P_{W, t}^{H}}{P_{R, t}^{H}} G+\left(1-\kappa_{t}\right) \frac{S_{t} m_{t}^{*}}{P_{R, t}^{H}} M_{t+1}=e_{t} a_{t}+(1-\eta) V_{t}-\zeta
$$

\section{Balance of payments}

$$
P_{W, t}^{M *} a_{t}+P_{W, t}^{M *} C_{t}^{X}+\frac{\Delta B_{t+1}^{F}}{S_{t}}=P_{W, t}^{M *} C_{t}^{M}+m_{t}^{*} M_{t}+\frac{i_{t-1} B_{t}^{F}}{S_{t}}
$$

\section{Interest parity condition}

$$
\mathbb{E}_{t}\left[\left(1+i_{t}\right) \frac{P_{t}}{P_{t+1}}\right]=\mathbb{E}_{t}\left[1+r_{t+1}^{*}\right]\left(\frac{\mathbb{E}_{t}\left[e_{t+1}\right]}{e_{t}}\right)^{\gamma} \phi\left(\frac{B_{t}^{F} / P_{t}}{Y_{t}}\right)
$$

\section{Shocks}

$$
\begin{aligned}
\ln \left(1+A_{t}\right)-\ln (1+\widehat{A}) & =\rho^{A}\left[\ln \left(1+A_{t-1}\right)-\ln (1+\widehat{A})\right]+\eta_{t}^{A} \\
\ln \left(1+m_{t}^{*}\right)-\ln \left(1+\widehat{m}^{*}\right) & =\rho^{m^{*}}\left[\ln \left(1+m_{t-1}^{*}\right)-\ln \left(1+\widehat{m}^{*}\right)\right]+\eta_{t}^{m^{*}}
\end{aligned}
$$

\section{Policy rules}

$$
\begin{gathered}
\frac{1+i_{t}}{1+\widehat{r}}=\left(\frac{1+i_{t-1}}{1+\widehat{r}}\right)^{\gamma_{i}}\left(\frac{1+\mathbb{E}_{t}\left[\pi_{t+1}\right]}{1+\pi^{\Theta}}\right)^{\gamma_{E \pi}}\left(\frac{1+\pi_{t}}{1+\pi^{\Theta}}\right)^{\gamma_{\pi}}\left(\frac{Y_{t}}{Y^{\Theta}}\right)^{\gamma_{y}}\left(\frac{S_{t}}{S^{\Theta}}\right)^{\gamma_{S}} \text { or } \quad S_{t}=S^{\Theta} \\
\kappa_{t}=\kappa \quad \text { or } \quad \kappa_{t}=\kappa\left(\frac{\widehat{m}}{m_{t}}\right)^{\Omega}
\end{gathered}
$$




\section{Appendix 3 List of variables and parameters}

\begin{tabular}{|c|c|}
\hline$A_{t}$ & Total factor productivity (weather) \\
\hline$a_{t}$ & Real net budgetary aid in foreign currency terms \\
\hline$\alpha_{L}$ & Labour distribution parameter \\
\hline$\alpha_{M}$ & Fertiliser distribution parameter \\
\hline$B_{t}$ & Farmers' nominal borrowings/'bonds' sold \\
\hline$B_{t}^{F}$ & Farmers' nominal bonds held by foreign investors \\
\hline$B_{t}^{H}$ & Farmers' nominal bonds held by domestic investors \\
\hline$\beta$ & Quarterly discount factor \\
\hline$C_{t}$ & Domestic consumption index \\
\hline$C_{t}^{H}$ & Domestic consumption of domestic goods \\
\hline$C_{t}^{M}$ & Domestic consumption of imported goods \\
\hline$C_{t}^{X}$ & Exports \\
\hline$\delta$ & $(\Sigma-1) / \Sigma$ \\
\hline$e_{t}$ & Real exchange rate \\
\hline$\eta$ & Farmer survival rate \\
\hline$\eta_{t}^{A}$ & Shock to total factor productivity (weather) \\
\hline$\eta_{t}^{m *}$ & Shock to foreign real fertiliser price \\
\hline$i_{t}$ & Domestic nominal interest rate \\
\hline$G$ & Government consumption \\
\hline$\gamma$ & Distribution parameter for domestic retail goods in domestic consumption \\
\hline$\gamma_{i}$ & Interest rate-smoothing weight in interest rate rule \\
\hline$\gamma_{E \pi}$ & Expected-inflation weight in interest rate rule \\
\hline$\gamma_{\pi}$ & Inflation weight in interest rate rule \\
\hline$\gamma_{S}$ & Nominal exchange rate weight in interest rate rule \\
\hline$\gamma_{y}$ & Output weight in interest rate rule \\
\hline$\kappa$ & Proportion of fertiliser cost not subsidised \\
\hline$L_{t}$ & Labour employed \\
\hline$\lambda_{t}$ & Lagrange multiplier on household budget constraint \\
\hline$\lambda^{p}$ & Sensitivity of price of domestic retail goods to marginal cost of production \\
\hline$M_{t}$ & Real units of fertiliser \\
\hline$m_{t}$ & Domestic real CPI fertiliser price \\
\hline$m_{t}^{*}$ & Foreign real fertiliser price \\
\hline$\mu$ & Domestic retailers' steady-state markup over wholesale prices \\
\hline$\mu_{f}$ & Foreign retailers' markup over wholesale prices \\
\hline$N_{t}$ & Real units of farmers' net worth \\
\hline$\nu$ & Inverse of intertemporal elasticity of substitution \\
\hline$\Omega$ & Sensitivity of fertiliser subsidy to fertiliser price \\
\hline$\omega_{t}$ & Idiosyncratic shock to farm productivity \\
\hline $\bar{\omega}_{t}$ & Bankruptcy threshold of idiosyncratic shock to farm productivity \\
\hline$P_{t}$ & Domestic CPI \\
\hline
\end{tabular}




\begin{tabular}{|c|c|}
\hline$P_{R, t}^{H}$ & Nominal price of domestic retail goods in domestic currency \\
\hline$P_{W, t}^{H}$ & Nominal price of domestic wholesale goods in domestic currency \\
\hline$P_{R, t}^{M}$ & Nominal price of imported retail goods in domestic currency \\
\hline$P_{R, t}^{M *}$ & Nominal price of foreign retail goods in foreign currency \\
\hline$P_{W, t}^{M}$ & Nominal price of foreign wholesale goods in domestic currency \\
\hline$P_{W, t}^{M *}$ & Nominal price of foreign wholesale goods in foreign currency \\
\hline$P_{W, t}^{Q}$ & Wholesale price index for $Q_{t}$ \\
\hline$P_{W, t}^{X}$ & Nominal price of domestic wholesale goods for the export market \\
\hline$P_{W, t}^{Y}$ & Wholesale price index for $Y_{t}$ \\
\hline$\phi$ & Domestic country risk premium parameter \\
\hline$\pi_{t}$ & CPI inflation rate \\
\hline$\pi^{\Theta}$ & Inflation target \\
\hline$\psi$ & Scaling parameter for $Q_{t}$ \\
\hline$Q_{t}$ & Composite domestic output for domestic consumption and export \\
\hline$r_{t}$ & Domestic real interest rate \\
\hline$r^{*}$ & Foreign real interest rate \\
\hline $\bar{R}_{t}^{M}$ & Gross non-default interest rate on loans to farmers \\
\hline$r_{t}^{M}$ & 'Return on fertiliser' \\
\hline$\rho$ & Elasticity of substitution between domestic and foreign retail goods \\
\hline$\rho^{A}$ & Persistence of total factor productivity (weather) \\
\hline$\rho^{m *}$ & Persistence of foreign real fertiliser price \\
\hline$S_{t}$ & Nominal exchange rate (increase $=$ depreciation) \\
\hline$S^{\Theta}$ & Nominal exchange rate target \\
\hline$s_{t}$ & External finance premium \\
\hline$S_{M}$ & Fertiliser share of national income \\
\hline$\Sigma$ & Fertiliser/labour elasticity of substitution \\
\hline$\sigma$ & Elasticity of transformation between domestic and export markets \\
\hline$\sigma_{A}^{2}$ & Variance of shock to total factor productivity \\
\hline$\sigma_{m^{*}}^{2}$ & Variance of shock to foreign real price of fertiliser \\
\hline$\sigma_{\omega}^{2}$ & Variance of idiosyncratic shock to farm productivity \\
\hline$\varsigma$ & Preference for leisure relative to consumption \\
\hline$\tau$ & 'Monitoring cost' paid in case of farm bankruptcy \\
\hline$\theta$ & Calvo parameter (quarterly probability of price not changing) \\
\hline$\vartheta$ & Elasticity of demand facing retailers \\
\hline$V_{t}$ & Farmers' aggregate retained earnings \\
\hline$W_{t}$ & Nominal wage \\
\hline$\xi$ & Retailers' fixed cost \\
\hline$Y_{t}$ & Real output \\
\hline$Y^{\Theta}$ & Output target \\
\hline$\zeta$ & Bequest from dying farmers to new farmers \\
\hline
\end{tabular}




\section{References}

Adam, C.S., O'Connell, S.A., and Buffie, E., (2008). Aid volatility, monetary policy rules and the capital account in African economies. World Economy and Finance Research Programme Working Paper WEF0037.

Adam, C.S., O'Connell, S.A., Buffie, E., and Patillo, C., (2009). Monetary Policy Rules for Managing Aid Surges. Review of Development Economics. 13(3).464-490.

Adam, C.S., Maturu, B.O., Ndung'u, N.S., O'Connell, S.A., (2010). Building a Kenyan Monetary Regime for the Twenty-first Century. In Adam, C.S., Collier, P., and Ndung'u, N.S, (2010). Kenya: Policies for Prosperity. Oxford: Oxford University Press.

Adjemian, S., Bastani, H., Juillard, M., Karamé, F., Mihoubi, F., Perendia, G., Pfeifer, J., Ratto, M., and Villemot, S., (2011). Dynare: Reference Manual, Version 4. Dynare Working Papers 1. CEPREMAP.

Aguiar, M. and Gopinath, G., (2007). Emerging Market Business Cycles: The Cycle Is the Trend. Journal of Political Economy. 115(1). 69-102.

Anand, R. and Prasad, E.S., (2010). Optimal Price Indices for Targeting Inflation Under Incomplete Markets. IMF Working Paper 10/200.

Ariga et al., (2006). Factors Driving the Growth in Fertilizer Consumption in Kenya, 1990-2005: Sustaining the Momentum in Kenya and Lessons for Broader Replicability in Sub-Saharan Africa. Egerton University Working Paper xx/2006.

Ariga et al., (2008). Trends and Patterns in Fertilizer Use by Smallholder Farmers in Kenya, 1997-2007. Egerton University Working Paper 28/2008.

Aysun, U., (2008). Automatic stabilizer feature of fixed exchange rate regimes. Emerging Markets Review. 9(4). 302-328.

Aysun, U., Brady, R., and Honig, A., (2011). Financial Frictions and the Credit Channel of Monetary Transmission. Mimeo.

Bernanke, B.S., Gertler, M., and Gilchrist, S., (1996). The Financial Accelerator and the Flight to Quality. Review of Economics and Statistics. 78(1). 1-15.

Bernanke, B.S., Gertler, M., and Gilchrist, S., (1999). The Financial Accelerator in a Quantitative Business Cycle Framework. In Handbook of Macroeconomics, Vol. 1. 134193. North Holland.

Buffie, E.F., Berg, A., Patillo, C., Portillo, R., and Zanna, L.-F., (2012). Public Investment, Growth, and Debt Sustainability: Putting Together the Pieces. IMF Working Paper $12 / 144$.

Buffie, E.F., Airaudo, M., and Zanna, L.-F., (2013). Inflation Targeting and Exchange Rate Management in Less Developed Countries. Mimeo.

Calvo, G., (1983). Staggered Prices in a Utility-Maximising Framework. Journal of Monetary Economics. 12(3). 383-98.

Cantore, C., and Levine, P., (2012). Getting normalization right: Dealing with 'dimensional constants' in macroeconomics. Journal of Economic Dynamics \& Control. 36(12). 1931-49.

Carlstrom, C.T. and Fuerst, T. S., (1997). Agency Costs, Net Worth, and Business Fluctuations - A Computable General Equilibrium Analysis. American Economic Review. 87(5). 893-910.

Dobrinsky, R., Korosi, G., Markov, N., and Halpern, L., (2006). Price markups and returns to scale in imperfect markets: Bulgaria and Hungary. Journal of Comparative Eco nomics. 34. 92-110.

Drummond, P.F.N., Aisen, A., Alper, E., Fuli., E., and Walker, S.E.J., (2015). Toward a Monetary Union in the East African Community: Asymmetric Shocks, Exchange Rates, and Risk-Sharing Mechanisms. IMF African Department Paper.

Duflo, C. Kremer, M., and Robinson, J., (2008). How High Are Rates of Return to Fertilizer? Evidence from Field Experiments in Kenya. American Economic Review: Papers and Proceedings. 98(2). 482-488. 
Duflo, C. Kremer, M., and Robinson, J., (2011). Nudging Farmers to Use Fertilizer: Theory and Experimental Evidence from Kenya. American Economic Review. 101(6). 23502390.

Galí, J., and Gertler, M., (1999). Inflation Dynamics: A Structural Econometric Analysis. Journal of Monetary Economics. 44(2). 195-222.

García-Cicco, J., Pancrazi, R., and Uribe, M., (2010). Real Business Cycles in Emerging Countries? American Economic Review. 100(5). 2510-2531.

Gertler, M., Gilchrist, S., and Natalucci, F.M., (2003). External Constraints on Monetary Policy and the Financial Accelerator. NBER Working Paper 10128.

Gertler, M., Gilchrist, S., and Natalucci, F.M., (2007). External Constraints on Monetary Policy and the Financial Accelerator. Journal of Money, Credit and Banking. 39(2-3). 295-330.

Islam, A.S.M.N. and Islam, S.M.F., (2010). Factor Demand in the Healthy Rice Seed Use in Boro and T. Aman - A Case Study of Bangladesh. Bangladesh Journal of Agricultural Research. 35(2) 297-312.

Karugia, J., Ndirangu, L., Nyangito, H., and Suri, T., (2010). Policy Options for Agriculture Growth in Kenya. In Adam, C.S., Collier, P., and Ndung'u, N.S. Kenya: Policies for Prosperity. Oxford: Oxford University Press.

Lamb, R.L., (2003). Fertilizer Use, Risk, and Off-Farm Labor Markets in the Semi-Arid Tropics of India. American Journal of Agricultural Economics. 85(2). 359-371.

Laxton, D. and Pesenti, P., (2003). Monetary Policy Rules for Small, Open, Emerging Economies. Journal of Monetary Economics. 50(5). 1109-1146.

León-Ledesma, M.A., McAdam, P., and Willman, A., (2010). Identifying the Elasticity of Substitution with Biased Technical Change. American Economic Review. 100(4). 1330-1357.

León-Ledesma, M.A., McAdam, P., and Willman, A., (2015). Production Technology Estimates and Balanced Growth. Oxford Bulletin of Economics and Statistics. 77(1). 40-65.

Levin, A., Wieland, V., Williams, J., (2003). The performance of forecast-based monetary policy rules under model uncertainty. American Economic Review. 93(3). 622-645.

Morris, M., Kelly. V.A., Kopicki, R.J., and Byerlee, D., (2007). Fertilizer Use in African Agriculture: Lessons Learned and Good Practice Guidelines. Washington, DC: The World Bank.

Ozkan, F.G. and Unsal, D.F., (2010). External Finance, Sudden Stops, and Financial Crisis: What is Different this Time? IMF Working Paper 10/158.

Portillo, R., Zanna, F., O'Connell, S., and Peck, R., (2015). Implications of Food Subsistence for Monetary Policy and Inflation. Mimeo.

Schmitt-Grohé, S. and Uribe, M., (2007). Optimal Simple and Implementable Monetary and Fiscal Rules. Journal of Monetary Economics. 54(6). 1702-1725.

Taylor, J., (1993). Discretion versus policy rules in practice. Carnegie-Rochester Conference Series on Public Policy. 39. 195-214.

Townsend, R.M. (1979). Optimal Contracts and Competitive Markets with Costly State Verification. Journal of Economic Theory. 21(2). 265-293. 